\author{
KEIO/KYOTO JOINT \\ GLOBAL CENTER OF EXCELLENCE PROGRAM \\ Raising Market Quality-Integrated Design of "Market Infrastructure"
}

KEIO/KYOTO GLOBAL COE DISCUSSION PAPER SERIES

\author{
DP2011-006
}

\title{
A New Model for Calculating Required Return on Investment
}

\author{
Yukitami Tsuji*
}

\begin{abstract}
It is widely accepted that the required return on investment is regarded as the weighted average cost of capital. The method for deciding whether an investment should be executed relies on the weighted average cost of capital; for example, NPV or IRR is presented in many textbooks as fundamental consideration. This method is theoretically appropriate in only a few models, such as the Modigliani-Miller(1963) hypothesis. Because other factors, such as financial distress costs and agency costs, are now generally recognized and applied, the method must be modified. How do we decide whether to implement an investment? This study provides an alternative to the weighted average cost of capital. The new method endogenously calculates the required return from a model that extends a bankruptcy cost model to consider agency costs.
\end{abstract}

*Yukitami Tsuji

Faculty of Business and Commerce, Keio University

\author{
KEIO/KYOTO J OINT GLOBAL COE PROGRAM \\ Raising Market Quality-Integrated Design of "Market Infrastructure" \\ Graduate School of Economics and Graduate School of Business and Commerce, \\ Keio University \\ 2-15-45 Mita, Minato-ku, Tokyo 108-8345, Japan \\ Institute of Economic Research, \\ Kyoto University \\ Yoshida-honmachi, Sakyo-ku, Kyoto 606-8501, Japan
}




\title{
A New Model for Calculating Required Return on
}

\section{Investment}

\author{
Yukitami Tsuji
}

July 5, 2011 (Third Edition)

\begin{abstract}
It is widely accepted that the required return on investment is regarded as the weighted average cost of capital. The method for deciding whether an investment should be executed relies on the weighted average cost of capital; for example, NPV or IRR is presented in many textbooks as fundamental consideration. This method is theoretically appropriate in only a few models, such as the Modigliani-Miller(1963) hypothesis. Because other factors, such as financial distress costs and agency costs, are now generally recognized and applied, the method must be modified. How do we decide whether to implement an investment? This study provides an alternative to the weighted average cost of capital. The new method endogenously calculates the required return from a model that extends a bankruptcy cost model to consider agency costs.
\end{abstract}

\section{Introduction}

This study proposes a method for calculating the required return on investment in a corporate capital structure model. The required return on investment is a cut-off rate or a hurdle rate when deciding whether an investment is executed or not. If a firm employs the IRR method for its decision-making, it adopts investment opportunities for which their internal rates of return are above their required return. When a firm uses the NPV method, a discount rate to compute its net present value determines the required return.

For brevity we begin by summarizing an investment decision that depends on the IRR method. In the explanation that uses the NPV method, some details must change, but the 
same basic argument holds. The IRR method requires that a rate of return on investment is expected. A simple example is useful to clarify the matter. Suppose that immediately after executing an investment of $\$ 100$, a firm predicts the increase in earnings before interest and $\operatorname{tax}(\mathrm{EBIT})$ at $\$ 20$. Then the after-tax expected rate of return is expressed as $(1-\tau) 20 \%$, where $\tau$ is a corporate tax rate. It is now common sense among business and academic circles that the required return to be compared with this expected rate of return is the weighted average cost of capital, defined as

$$
C C_{t a x}=\frac{S_{L}}{V_{L}} \rho_{S}+\frac{B}{V_{L}}(1-\tau) \rho_{B},
$$

where $S_{L}$ is a equity value, $B$ is a debt value, and $V_{L}$ is a firm value. $\rho_{S}$ is the cost of capital on equity, which is usually computed through the CAPM. $\rho_{B}$ is the cost of capital on debt. Instead of the required return on debt-holders, an average borrowing rate the firm incurs is substituted into $\rho_{B}$.

If a firm is listed on a stock exchange, it is easy to determine the value of the required return through Equation (1) from data on the firm's stock prices and financial reports. $\rho_{S}$ and $\rho_{B}$ are calculated as described above. $S_{L}$ is the market valuation of equity. A proxy variable for $B$ is the amount of debt on the balance sheet. Hence, if we want to know the required return, there is no trouble that some economic models of real investment or quantitative analyses in the management have to be estimated. We can get it with minimal difficulty, as if it were decided exogenously outside the firm.

This explanation works well because both the expected return and the required return are easy to obtain. Whether this method preserves theoretical consistency, however, depends on a particular model. Intuitively speaking, this is the Modigliani and Miller(1963) model, which assumes corporate income tax. As long as your analysis assumes what Modigliani and Miller(1963) supposed, the explanation above is adequate. However, when you extend your model to consider a factor that Modigliani and Miller(1963) did not assume, its logic fails.

The dominant evolving theory discredits the hypothesis that Modigliani and Miller(1963) derived. Several factors that the MM hypothesis did not include — for example, the financial distress costs, the bankruptcy costs, and the agency costs - are widely recognized among business and academic circles. Then if you adhere to the required return defined in Equation (1), formulation of the expected rate of return that is to be compared with it is confusing. This expected return must include not only a change in the EBIT but also the effects of these factors. The formulation provides you with a strange number that deviates from $(1-\tau) 20 \%$. 
The required return on investment is formulated as the WACC of Equation (1) because you can compare the WACC with the expected return that is computed with a simple and plausible $(1-\tau) 20 \%$. ${ }^{* 1}$ When we extend Modigliani and Miller(1963) to add the bankruptcy costs and the agency costs in order to explain actual capital structure, the question arises: How do we make decisions about investment?

It is conventional wisdom in business that the expected return on investment is simply calculated such as $(1-\tau) 20 \%$, which means that only a change in EBIT is considered. Under the model that considers bankruptcy costs and agency costs, the required return that should be compared with this expected return is no longer an exogenous value given by Equation (1). How much is the required return that should be compared with $(1-\tau) 20 \%$ ? We need to derive it endogenously from the model. If you use Equation (1) as the required return, your investment decision is suboptimal and risks a large distortion.

This study provides an alternative to the WACC as the required return: Required return depends on the capital structure model based on extending a bankruptcy cost model to including agency costs. Under this model, we calibrate a value of the required return as a rate of return below which existing shareholders have a loss on firm's investment. This computation method reveals an interesting characteristic of investment financing.

If a capital structure model has homogeneity of degree one with respect to firm's size, the investment strategy that maintains constant return to scale seems to be optimal. In that case, the required return is equal to firm's earnings ratio. However, when a firm maximizes the wealth of shareholders, this strategy is not always optimal, depending upon how it finances the investment. We assume that cash to execute the investment is raised from outside investors. The investment that makes a firm purely scaled up must issue a mix of new debt and new equity, the proportion of which is the same as the corporate capital structure. As long as old debt-holders do not make a loss, this pure scaling-up strategy is optimal. However, the firm can give old shareholders greater gains at the sacrifice of the old debt-holders, issuing more debt in financing the investment. New debt exceeding the pure scaling-up case dilutes the value of old debt and increases wealth transfer from old debt-holders to shareholders. As a result, the required return on investment becomes smaller than the firm's earnings ratio. Therefore, even if a capital structure model has constant return to scale, the pure scaling-up

\footnotetext{
*1 The argument is the conclusion of discussion among Arditti-Levy(1977), Ben-Horim(1979) and BoudreauxLong(1979). Levy-Sarnat(1990) stands in the same viewpoint.
} 
investment strategy is not necessarily optimal when a firm can issue securities without any restriction.

The method of financing investment changes the required return. Investment opportunity, which otherwise would be rejected, might be executed because shareholders are compensated with the wealth transfer from old debt-holders. The required return on investment decreases by the wealth transfer. Maximizing wealth transfer through all debt financing minimizes the required return. When financing investments, all debt is preferred to the mix of debt and equity. Even if the firm has the optimal capital structure, the pecking order hypothesis holds for investment financing. This is the most interesting aspect of this model in that optimal capital structure is compatible with the pecking order hypothesis.

Another feature of this study is that we compared the required return estimated from this model with $C C_{\operatorname{tax}}$ of Equation (1) for more than 500 firms, which are listed on the Tokyo Stock Exchange among manufacturing industries. Although these values move together to some extent, their co-movement is not very strong. There is a period when $C_{\text {tax }}$ is $20 \%$ larger than the estimated required return in terms of sample averages. Since some firms overestimate their required return on investment, using the WACC is not always adequate.

This study explains a model of capital structure in Section 2, where we do not consider firm's investment explicitly. In Section 3, adding investment to the model, we provide the method for calculating the required return, and investigate how a firm should finance investments. We show some simulation results in Section 4 and apply the method to actual firms in Section 5. Section 6 presents the conclusion.

\section{A Model of Capital Structure}

\subsection{Valuation of Equity and Debt}

We begin with a basic model, the purpose of which is to derive optimal capital structure at the outset. ${ }^{* 2}$ This is a one-period model, as summarized in Figure 1 . At the beginning of a period, a firm is founded and issues debt and shares of stock. The firm purchases assets and starts up in business. Investors are debt-holders and shareholders. The person who makes the decisions for the firm is a manager who works on behalf of the shareholders. At the end of the

\footnotetext{
${ }^{* 2}$ For detailed explanation, see Tsuji(2009).
} 


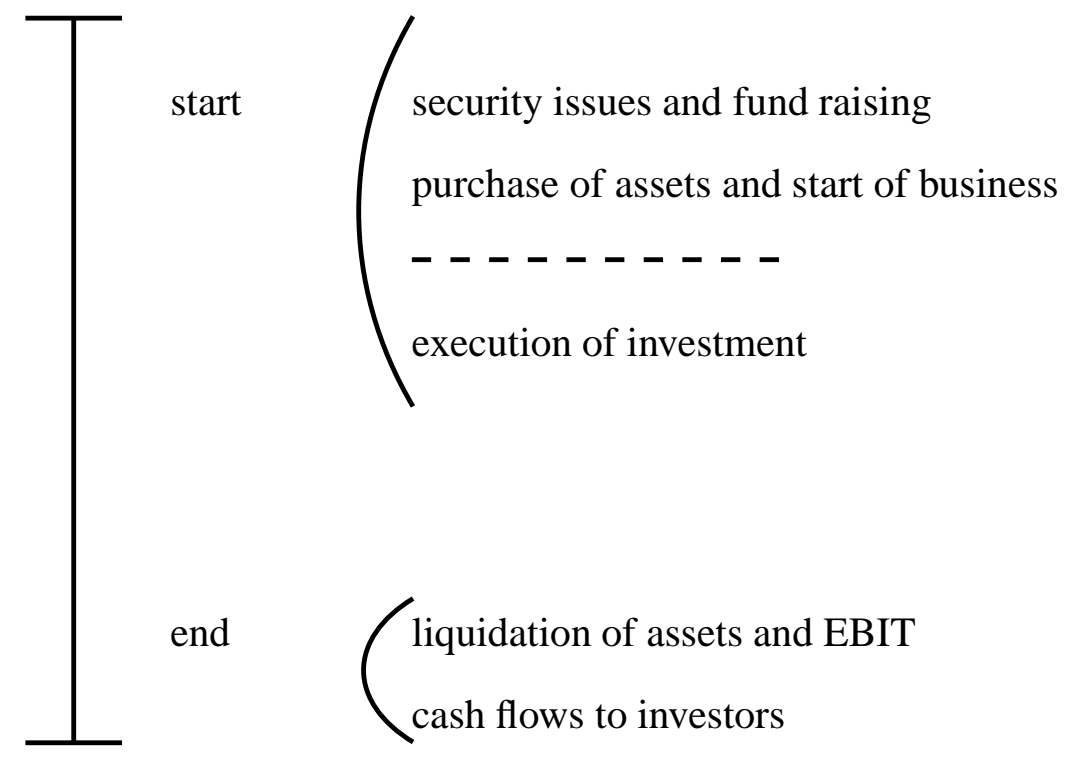

Figure 1 Time Structure of the Model

period when the firm is liquidated, EBIT over the period and proceeds from the sale of assets are distributed among the investors. The values of equity and debt issued at the beginning are denoted as $S_{L}$ and $B$. The sum of $S_{L}$ and $B$ is a firm value $V_{L} . V_{L}$ also represents the value of assets the firm holds at the beginning, because we assume that the firm purchases them with all the funds it raises.

In this study, the debt, which is a senior claim, promises a payment $L$ to debt-holders at the end of the period. $L$ consists of the principal and interest of the debt. The sum of the EBIT and the liquidation value is $\tilde{Z}$ which is firm's cash flow distributed to debt-holders and shareholders at the end of the period. $\tilde{Z}$ is a random variable that follows a normal distribution $\mathrm{N}\left(\mu_{Z}, \sigma_{Z}\right) .{ }^{* 3} \mu_{Z}$ is an expected value and $\sigma_{Z}$ is standard deviation. If a realized value $Z$ of $\tilde{Z}$ is greater than $L$, the firm pays $L$ to the debt-holders first, then corporate income taxes, and finally the residual is paid to the shareholders as dividends. However, if $Z$ is less than $L$, the firm is in default and goes bankrupt. Then bankruptcy costs that amount to $K$ are incurred. This study assumes bankruptcy costs to be proportional to the firm value, $K=k V_{L}$.

Suppose that the corporate income tax is an asymmetric type of tax loss offset provisions. Asymmetric income tax is such that taxable income is charged at the rate of $\tau$ if and only

\footnotetext{
${ }^{* 3}$ In this study, unlike ordinary notation such as $\mathrm{N}\left(\mu_{Z}, \sigma_{Z}^{2}\right)$, the second variable of $\mathrm{N}(\cdot, \cdot)$ denotes standard deviation, not variance.
} 
if it is positive. If taxable income is negative, the tax payment is zero. Taxable income is calculated as $Z-V_{L}-(L-B)$, where $Z-V_{L}$ is earnings from business activities, and $L-B$ is a deductible interest expense. When $Z$ is greater than $V_{L}+L-B$, the tax payment amounts to $\tau\left[Z-V_{L}-(L-B)\right]$. When $Z$ is less than $V_{L}+L-B$, the tax payment becomes zero since the taxable income is negative.

Shareholders' cash flow at the end of the period, $\tilde{Q}_{L S}$, is formulated as

$$
\tilde{Q}_{L S}= \begin{cases}\tilde{Z}-L-\tau\left(\tilde{Z}-V_{L}-[L-B]\right) & \text { for } Z \geq V_{L}+L-B, \\ \tilde{Z}-L & \text { for } V_{L}+L-B>Z \geq L, \\ 0 & \text { for } L>Z .\end{cases}
$$

Since shareholders have limited liability, $S_{L}=V_{L}-B>0$, this means that $V_{L}+L-B$ is always greater than $L$. There are three equations for $\tilde{Q}_{L S}$, depending on whether $\tilde{Z}$ is greater than $V_{L}+L-B$ or $L$. The first of Equation (2) is the case where the taxable income is positive; there is no bankruptcy. In the second of Equation (2), the taxable income is negative, but the firm does not go bankrupt. The third describes the case where the firm goes bankrupt. Then $\tilde{Z}$ belongs to the debt-holders, and the shareholders get nothing.

Debt-holders' cash flows are represented as $\tilde{Q}_{L B}$, the formula for which depends on whether the promised payment to debt, $L$, is greater than the bankruptcy costs, $K$. In the case where $L>K, \tilde{Q}_{L B}$ is

$$
\tilde{Q}_{L B}^{(L>K)}= \begin{cases}L & \text { for } Z \geq L, \\ \tilde{Z}-K & \text { for } L>Z \geq K, \\ 0 & \text { for } K>Z .\end{cases}
$$

The superscript shows $L>K$. When $Z \geq L$, debt-holders receive the promised payment $L$. When $Z$ is less than $L$, the firm goes bankrupt, and $\tilde{Z}$ belongs to the debt-holders who incur the bankruptcy costs $K$. If $Z$ is less than $K$, debt-holders' cash flow from the firm becomes zero because of their limited liability.

In the case of $K \geq L$, the formula for $\tilde{Q}_{L B}$ becomes

$$
\tilde{Q}_{L B}^{(K \geq L)}= \begin{cases}L & \text { for } Z \geq L, \\ 0 & \text { for } L>Z .\end{cases}
$$

This second equation represents the bankruptcy case where there is no cash flow because of the bankruptcy costs and the limited liability. 
The equity value $S_{L}$ and the debt value $B$ at the beginning of the period are derived from their cash flows at the end of the period. This study employs the CAPM in pricing securities. The certainty equivalent approach of the CAPM can be applied to their valuation:

$$
\begin{gathered}
S_{L}=\frac{\mathrm{E}\left(\tilde{Q}_{L S}\right)-\lambda \operatorname{cov}\left(\tilde{R}_{M}, \tilde{Q}_{L S}\right)}{1+R_{F}}, \\
B= \begin{cases}{\left[\mathrm{E}\left(\tilde{Q}_{L B}^{(L>K)}\right)-\lambda \operatorname{cov}\left(\tilde{R}_{M}, \tilde{Q}_{L B}^{(L>K)}\right)\right] /\left(1+R_{F}\right)} & \text { for } L>K, \\
{\left[\mathrm{E}\left(\tilde{Q}_{L B}^{(K \geq L)}\right)-\lambda \operatorname{cov}\left(\tilde{R}_{M}, \tilde{Q}_{L B}^{(K \geq L)}\right)\right] /\left(1+R_{F}\right)} & \text { for } K \geq L,\end{cases}
\end{gathered}
$$

where $R_{F}$ is a riskless interest rate, $\tilde{R}_{M}$ is the rate of return on the market portfolio, and

$$
\lambda=\frac{\mathrm{E}\left(\tilde{R}_{M}\right)-R_{F}}{\sigma\left(\tilde{R}_{M}\right)^{2}} .
$$

The means and covariance in Equations (5) and (6) are computed through partial moment formulas:

$$
\begin{gathered}
\mathrm{E}\left(\tilde{Q}_{L S}\right)=\mu_{Z}\left[1-\tau+\tau F\left(V_{L}+L-B\right)-F(L)\right]+\sigma_{Z}^{2}\left[f(L)-\tau f\left(V_{L}+L-B\right)\right] \\
-L[1-F(L)]+\tau\left(V_{L}+L-B\right)\left[1-F\left(V_{L}+L-B\right)\right] \\
\operatorname{cov}\left(\tilde{R}_{M}, \tilde{Q}_{L S}\right)=\operatorname{cov}\left(\tilde{R}_{M}, \tilde{Z}\right)\left[1-\tau+\tau F\left(V_{L}+L-B\right)-F(L)\right] \\
\mathrm{E}\left(\tilde{Q}_{L B}^{(L>K)}\right)=L[1-F(L)]-K[F(L)-F(K)] \\
+\mu_{Z}[F(L)-F(K)]-\sigma_{Z}^{2}[f(L)-f(K)] \\
\operatorname{cov}\left(\tilde{R}_{M}, \tilde{Q}_{L B}^{(L>K)}\right)=\operatorname{cov}\left(\tilde{R}_{M}, \tilde{Z}\right)[F(L)-F(K)+K f(L)] \\
\mathrm{E}\left(\tilde{Q}_{L B}^{(K \geq L)}\right)=L[1-F(L)] \\
\operatorname{cov}\left(\tilde{R}_{M}, \tilde{Q}_{L B}^{(K \geq L)}\right)=\operatorname{cov}\left(\tilde{R}_{M}, \tilde{Z}\right) L f(L)
\end{gathered}
$$

where $f(\cdot)$ is the density function of the normal distribution $\mathrm{N}\left(\mu_{Z}, \sigma_{Z}\right)$, and $F(\cdot)$ is the cumulative distribution function.

\subsection{Modeling the Agency Costs of Debt}

The valuation of equity and debt in Section 2.1 is premised on the CAPM, which depends on the assumption that investors have perfect information in capital markets. The agency costs 
are caused by managerial discretion or investment distortion after a firm issues its security. Thus, we assume that capital markets are perfect, at least when securities are issued. Other studies about agency costs also assume that investors have perfect information in capital markets at the beginning of a period. For example, Leland(1998) and Morellec(2004) employ continuous time pricing models for security valuation, taking agency costs into account. This model adopts the CAPM instead of continuous time models.

At the beginning of a period, a manager and all investors equally expect a correct probability distribution of $\tilde{Z}$, which means perfect information. Their expectation is reflected in the parameters: $\mu_{Z}, \sigma_{Z}$, and $\operatorname{cov}\left(\tilde{R}_{M}, \tilde{Z}\right) . L$ and $Z$, which is a realized value of $\tilde{Z}$, are assumed to be verifiable. This means that realized values of $\tilde{Q}_{L S}$ and $\tilde{Q}_{L B}$ are verifiable. Since verifiability makes manager's promise enforceable, investors become able to evaluate equity and debt as shown in Equations (5) and (6). The valuation assumes that cash flows the manager promises to investors, Equations (2) and (3) or (4), are verifiable and are impossible to breach.

We know from the means and covariance of Equations (5) and (6) that $S_{L}$ and $B$ are functions of several parameters: $L, \mu_{Z}, \sigma_{Z}, k, \tau, \lambda, R_{F}$, and $\operatorname{cov}\left(\tilde{R}_{M}, \tilde{Z}\right)$. What the manager is able to control directly in his/her decision making is assumed to be $L, \mu_{Z}$, and $\sigma_{Z}$. We focus on them in this model. ${ }^{* 4}$ The equity and debt values are denoted as

$$
\begin{aligned}
S_{L} & =S_{L}\left(L, \mu_{Z}, \sigma_{Z}\right), \\
B & =B\left(L, \mu_{Z}, \sigma_{Z}\right) .
\end{aligned}
$$

The firm value is the sum of these values and is defined as

$$
V_{L}\left(L, \mu_{Z}, \sigma_{Z}\right)=S_{L}\left(L, \mu_{Z}, \sigma_{Z}\right)+B\left(L, \mu_{Z}, \sigma_{Z}\right)
$$

How does this model account for managerial discretion, which causes the agency costs? The model reflects what the manager does in the probability distribution parameters, $\mu_{Z}$ and $\sigma_{Z}$. Needless to say, $\mu_{Z}$ and $\sigma_{Z}$ might be observable, but cannot be verified even if a realized value $Z$ is verifiable. After issuing securities, he/she can operate the firm aligned with his/her own target, so that $\mu_{Z}$ and $\sigma_{Z}$ attain the most advantageous value. These are not the best for investors. On the other hand, anticipating the manager's decision after issuing securities, the investors correctly forecast the values of $\mu_{Z}$ and $\sigma_{Z}$ that he/she will select. This is the

\footnotetext{
${ }^{* 4}$ There are other parameters which the manager influences indirectly; for example, $k$ and $\operatorname{cov}\left(\tilde{R}_{M}, \tilde{Z}\right)$. We assume that the parameters other than $L, \mu_{Z}$, and $\sigma_{Z}$ are given and constant.
} 
meaning of "perfect information" in this model. While the manager might guarantee these values, his/her promises are not enforceable and not trusted by the investors because they are not verifiable. Investors evaluate securities, predicting the values of $\mu_{Z}$ and $\sigma_{Z}$ that he/she will choose in line with his/her objective.

The model in this study explicitly considers agency costs between debt-holders and shareholders. Hereafter, we designate them as the agency costs of debt. When discussing the agency costs of debt, a manager is assumed to be a faithful agent for shareholders. This model assumes that his/her objective is to maximize the wealth of shareholders. Then the incentives of asset substitution and debt overhang give rise to the agency costs. With regard to asset substitution, even if it reduces EBIT, the manager can use a business strategy that increases the firm's risk enough to increase the equity value. Debt overhang makes the manager abandon a business strategy that improves the EBIT but that might decrease the equity value owing to leakage into debt.

If a firm is unleveraged, asset substitution and debt overhang does not arise, and all the strategies that increase the EBIT are used. The result of this decision making by the unleveraged firm is the expected value of its cash flow, $\omega_{Z}$. On the other hand, if the firm is leveraged and has to pay $L$ at the end of a period, $L$ makes $\mu_{Z}$ lower than $\omega_{Z}$ due to these incentives. Hence $\mu_{Z}$ is regarded as a function of $\omega_{Z}$ and $L$. For the brevity of this model, we assume that $\mu_{Z}$ is a linear function of $L$ through the incentives that cause the agency costs:

$$
\mu_{Z}=\omega_{Z}-\alpha L, \quad \alpha>0
$$

where $\alpha$ means the decline in $\mu_{Z}$ from $\omega_{Z}$ with a unit increase of a debt burden. So $\alpha$ is the marginal effect of the agency costs of debt.

At the beginning of a period, the manager chooses firm's capital structure to maximize the firm's value. The capital structure is derived from $L$, under which he/she decides to maximize cash the firm raises from capital markets:

$$
L^{*}=\arg \max _{L}\left\{S_{L}\left(L, \mu_{Z}, \sigma_{Z}\right)+B\left(L, \mu_{Z}, \sigma_{Z}\right)\right\} .
$$

Next, during the period just after the beginning, the manager behaves so as to maximize the equity value. With the firm taking more risk in managements, the equity value increases to the detriment of the debt value. Through the incentive of this asset substitution, he/she chooses 
$\sigma_{Z}$, the value of which leads to the maximization of $S_{L} \cdot{ }^{* 5}$

$$
\sigma_{Z}^{*}=\arg \max _{\sigma_{Z}} S_{L}\left(L^{*}, \mu_{Z}, \sigma_{Z}\right)
$$

In sum, the optimal decision making strategy for the manager is to decide the values of these three parameters, $L, \mu_{Z}$, and $\sigma_{Z}$, which satisfy Equations (7), (8), and (9). We denote these solutions as $L^{*}, \sigma_{Z}^{*}$, and $\mu_{Z}^{*}$. The manager favors their values the most, carrying out his/her objective. Then investors can price the securities, perfectly knowing them. Rewrite the simultaneous equations, thus:

$$
\begin{gathered}
\frac{\partial}{\partial \sigma_{Z}} S_{L}\left(L^{*}, \mu_{Z}^{*}, \sigma_{Z}^{*}\right)=0, \\
\frac{\partial}{\partial L} V_{L}\left(L^{*}, \mu_{Z}^{*}, \sigma_{Z}^{*}\right)=0, \\
\mu_{Z}^{*}=\omega_{Z}-\alpha L^{*}
\end{gathered}
$$

Although $L^{*}, \sigma_{Z}^{*}$, and $\mu_{Z}^{*}$ are endogenously decided with the equations, new exogenous parameters, $\omega_{Z}$ and $\alpha$, have appeared. Thus, by formulating the agency costs, the values of equity, debt, and firm become functions of $\omega_{Z}$ and $\alpha$;

$$
\begin{aligned}
S_{L} & =S_{L}\left(\omega_{Z}, \alpha ; L^{*}, \mu_{Z}^{*}, \sigma_{Z}^{*}\right), \\
B & =B\left(\omega_{Z}, \alpha ; L^{*}, \mu_{Z}^{*}, \sigma_{Z}^{*}\right), \\
V_{L} & =V_{L}\left(\omega_{Z}, \alpha ; L^{*}, \mu_{Z}^{*}, \sigma_{Z}^{*}\right) .
\end{aligned}
$$

\subsection{A Numerical Example}

This model cannot be solved analytically. In order to know features of the model, we have to depend on a numerical solution method. Here we explain a numerical example on which the model is to be solved.

We assume a one-period model where one period is a long term (for example, 10 years). A cash flow at the end of a period, $\tilde{Z}$, is the sum of EBIT for 10 years and the liquidation value of assets. One of the basic parameters to which we give a numerical value is $\omega_{Z}$, which is the cash flow at the end of the period when the firm is unleveraged and when there are no agency

\footnotetext{
${ }^{* 5}$ Note that the optimal value of $\sigma_{Z}$ can exist as an inner solution because $\tilde{Q}_{L S}$ has both convex and concave regions in the function of $\tilde{Z}$.
} 
Table 1 A Numerical Example

Exogenous Variables

\begin{tabular}{llllrrrrr}
\hline$\omega_{Z}$ & $\alpha$ & $k$ & $\tau$ & $\mathrm{E}\left(\tilde{R}_{M}\right)$ & $\sigma\left(\tilde{R}_{M}\right)$ & $R_{F}$ & $\lambda$ & $\operatorname{corr}\left(\tilde{R}_{M}, \tilde{Z}\right)$ \\
\hline 50.0 & 0.2 & 0.4 & 0.45 & 0.11 & 0.18 & 0.06 & 3.236 & 0.2 \\
\hline
\end{tabular}

Endogenous Variables

\begin{tabular}{cccccccc}
\hline$\mu_{Z}^{*}$ & $\sigma_{Z}^{*}$ & $L^{*}$ & $S_{L}$ & $B$ & $V_{L}$ & $D R$ & $R O A$ \\
\hline 47.41 & 23.66 & 12.93 & 10.51 & 6.42 & 16.93 & 0.379 & 0.1144 \\
\hline
\end{tabular}

N.B)E $\left(\tilde{R}_{M}\right), \sigma\left(\tilde{R}_{M}\right)$ and $R_{F}$ are numbers in the case of one period equals one year. $\lambda$ is computed after these are converted to the case of one period equals 10 years. $\omega_{Z}, \mu_{Z}^{*}$ and $\sigma_{Z}^{*} ! \$ L^{*}$ are numbers in the case of one period equals 10 years. $D R$ is the debt ratio $B / V_{L}$. $R O A$ is the earnings ratio, which is the before-tax value. $R O A$ converts $R_{R O A}$ computed by Equation (13) to the case of one period equals one year.

costs. Another parameter is $\alpha$, which is the marginal effect of the agency costs. We assume that $\omega_{Z}$ is 50 and that $\alpha$ is 0.2 .

For other parameters, the bankruptcy cost parameter $k$ is 0.4 , and the corporate income tax rate $\tau$ is 0.45 . Parameters related with capital markets are $\mathrm{E}\left(\tilde{R}_{M}\right)=0.11, \sigma\left(\tilde{R}_{M}\right)=0.18$, and $R_{F}=0.06$ if they are denoted as a one-year standard, and $\operatorname{corr}\left(\tilde{R}_{M}, \tilde{Z}\right)$ is 0.2 . The value of $11 \%$ for $\mathrm{E}\left(\tilde{R}_{M}\right)$ is the condition under which one period equals one year. Since this model assumes one period to be 10 years, this value must be converted to $(1.11)^{10}-1$, which is equal to 1.839 . That is, $\mathrm{E}\left(\tilde{R}_{M}\right)=1.839$ in the case of one period equals 10 years. For evaluating the expected rate of return and the riskless rate, the numerical value obtained after the conversion is employed. For standard deviation, $\sqrt{10}$ is multiplied by a one-year value. After these conversions, $\lambda$ becomes 3.236 .

The numerical example is summarized in Table 1 . With the exogenous variables given, endogenous variables are computed from this model. $\mu_{Z}^{*}=47.41, \sigma_{Z}^{*}=23.66$, and $L^{*}=12.93$ are solutions of the simultaneous equation system, Equations (10), (11) and (12). Values of $S_{L}, B$ and $V_{L}$ under these solutions are also written. $D R$ is the debt ratio $B / V_{L}$. $R O A$ is a firm's earnings ratio calculated from

$$
R_{R O A}=\frac{\omega_{Z}-V_{L}}{V_{L}}
$$

where $\omega_{Z}$ is total earnings during 10 years. $R O A$ in the table is converted from $R_{R O A}$ into the 
Table 2 Changes in $\omega_{Z}$

\begin{tabular}{ccccccccc}
\hline$\omega_{Z}$ & $\mu_{Z}^{*}$ & $\sigma_{Z}^{*}$ & $L^{*}$ & \multicolumn{1}{c}{$S_{L}$} & $B$ & $V_{L}$ & $D R$ & $R O A$ \\
\hline 40.0 & 37.93 & 18.92 & 10.35 & 8.41 & 5.13 & 13.54 & 0.379 & 0.1144 \\
45.0 & 42.67 & 21.28 & 11.64 & 9.46 & 5.78 & 15.23 & 0.379 & 0.1144 \\
50.0 & 47.41 & 23.66 & 12.93 & 10.51 & 6.42 & 16.93 & 0.379 & 0.1144 \\
55.0 & 52.15 & 26.02 & 14.23 & 11.56 & 7.06 & 18.62 & 0.379 & 0.1144 \\
60.0 & 56.90 & 28.38 & 15.52 & 12.61 & 7.70 & 20.31 & 0.379 & 0.1144 \\
\hline
\end{tabular}

N.B) Parameters other than $\omega_{Z}$ are the values of Exogenous Variables in Table 1.

case of a one-period equals one year standard. ${ }^{* 6}$ In the numerical example the earnings ratio is $11.44 \%$, which is the before-tax value.

The numerical example exhibits a feature of this model, scale homogeneity. Table 2 confirms that a firm is homogeneous of degree one with respect to $\omega_{Z}$. For example, if $\omega_{Z}$ increases from 50 to 60 , where new $\omega_{Z}$ is 1.2 times as large as the old one, then all variables such as $\mu_{Z}^{*}, \sigma_{Z}^{*}, L^{*}, S_{L}, B$, and $V_{L}$ increase by 1.2 times. Ratios like $D B$ and $R O A$ keep the same values. The scale homogeneity depends on assuming that Equation (12) is linear. It is unknown whether $\mu_{Z}^{*}$ is linearly related to $\omega_{Z}$ and $L^{*}$. If the relation is quadratic, homogeneity disappears. Although this is not necessary in the model, the assumption of homogeneity provides us with a special case that is useful in modeling firm's investment.

\section{Modeling Corporate Investment}

\subsection{Required Return on Investment}

In this section, corporate investment is added onto the basis of the model described in Section 2. It is assumed that new investment opportunities appear suddenly just after a firm has begun doing business. Should the firm realize these opportunities? In order to decide whether or not to execute investment, the firm has to know the required return on investment. How is this computed? We offer it through calculation, relying upon the model.

Now, it is necessary to assume that an investment opportunity appears suddenly and that investors and the firm do not know about it when the firm issues securities for the founda-

\footnotetext{
$* 6$ The value of $R O A$ in Table 1 is converted from $R_{R O A}$ in Equation (13) through $\left(1+R_{R O A}\right)^{\frac{1}{10}}-1$.
} 
tion. Since capital markets are perfect at the beginning of a period, the opportunity must be reflected in security valuation, and the investment must be included in the firm's decisions for starting up business. If so, however, we cannot study corporate investment explicitly because it is impossible to separate one investment decision from others. Although a dynamic model might overcome this problem, it makes calculation too complicated to be workable. In order to account for corporate investment in the framework of this simple one-period model, we must depend on this assumption, which may be unusual.

All the cash obtained through the issues at the beginning have already been used for the purchase of assets, and the firm has no money for the investment. The amount of investment that must be newly raised from investors is $I . I_{B}$ of this $I$ is debt issuance and remaining $I_{S}$ is equity issuance. So $I=I_{S}+I_{B}$. $I$ is assumed to be exogenously given. This model is able to optimally decide the proportion of debt to equity with the amount of investment $I$ given. For a while, in order to simplify our discussion, we also assume $I_{S}$ and $I_{B}$ to be exogenous.

The model in Section 2 represents the case where the firm has no investment. Superscript (0) is added to variables to indicate explicitly the no-investment case. The expected cash flow at the end of a period for an unleveraged firm is $\omega_{Z}^{(0)}$. The parameter that represents the effect of the agency costs is $\alpha$. Both of them are exogenous for the leveraged firm. Simultaneous equations to be solved are:

$$
\begin{gathered}
\frac{\partial}{\partial \sigma_{Z}} S_{L}\left(\omega_{Z}^{(0)}, \alpha ; L^{*(0)}, \mu_{Z}^{*(0)}, \sigma_{Z}^{*(0)}\right)=0, \\
\frac{\partial}{\partial L} V_{L}\left(\omega_{Z}^{(0)}, \alpha ; L^{*(0)}, \mu_{Z}^{*(0)}, \sigma_{Z}^{*(0)}\right)=0, \\
\mu_{Z}^{*(0)}=\omega_{Z}^{(0)}-\alpha L^{*(0)} .
\end{gathered}
$$

where $L^{*(0)}, \mu_{Z}^{*(0)}$ and $\sigma_{Z}^{*(0)}$ are solutions of the equations. Then, firm's business is such that a cash flow at the end is randomly distributed on $\mathrm{N}\left(\mu_{Z}^{*(0)}, \sigma_{Z}^{*(0)}\right)$. In addition, the firm promises $L^{*(0)}$ to debt-holders. As a result, the values of equity and debt are $S_{L}^{(0)}$ and $B^{(0)}$ :

$$
\begin{aligned}
& S_{L}^{(0)}=S_{L}\left(\omega_{Z}^{(0)}, \alpha ; L^{*(0)}, \mu_{Z}^{*(0)}, \sigma_{Z}^{*(0)}\right), \\
& B^{(0)}=B\left(\omega_{Z}^{(0)}, \alpha ; L^{*(0)}, \mu_{Z}^{*(0)}, \sigma_{Z}^{*(0)}\right) .
\end{aligned}
$$

An investment opportunity suddenly appears just after the firm has started up business. If the firm implements the investment, the distribution of the cash flow is changed to $\mathrm{N}\left(\mu_{Z}^{*(1)}, \sigma_{Z}^{*(1)}\right)$. Superscript ${ }^{(1)}$ indicates that investment is executed. Since the firm issues 
new debt, the promised payment to debt-holders at the end is also altered to $L^{*(1)}$. The perfect information in capital markets informs investors of these changes immediately. Hence new values of equity and debt are $S_{L}^{(1)}$ and $B^{(1)}$.

The parameters in the case of investment are $\mu_{Z}^{*(1)}, \sigma_{Z}^{*(1)}$, and $L^{*(1)}$. They are constrained by the agency costs of debt. First, the incentive of the asset substitution requires $\sigma_{Z}$ to maximize $S_{L}$ :

$$
\sigma_{Z}^{*(1)}=\arg \max _{\sigma_{Z}} S_{L}\left(L^{*(1)}, \mu_{Z}^{*(1)}, \sigma_{Z}\right)
$$

Next, through the linear relationship causes by the agency costs of debt, $\mu_{Z}^{*(1)}$ is related to $\omega_{Z}^{(1)}$, which is the expected cash flow when the unleveraged firm executes the same investment. The relationship shown in Equation (12) is rewritten as

$$
\mu_{Z}^{*(1)}=\omega_{Z}^{(1)}-\alpha L^{*(1)}
$$

There is no guarantee that this $\alpha$ remains unchanged after the investment is implemented. We assume that the $\alpha$ is the same regardless of investment. Lastly, $L^{*(1)}$ is concerned with financing the investment. Under these constraints, the values of equity and debt, $S_{L}^{(1)}$ and $B^{(1)}$, are functions in this manner:

$$
\begin{aligned}
& S_{L}^{(1)}=S_{L}\left(\omega_{Z}^{(1)}, \alpha ; L^{*(1)}, \mu_{Z}^{*(1)}, \sigma_{Z}^{*(1)}\right), \\
& B^{(1)}=B\left(\omega_{Z}^{(1)}, \alpha ; L^{*(1)}, \mu_{Z}^{*(1)}, \sigma_{Z}^{*(1)}\right) .
\end{aligned}
$$

Since the investment needs to finance $I_{B}$ with debt, the debt valuation is

$$
B^{(1)}-\frac{L^{*(0)}}{L^{*(1)}} B^{(1)}=I_{B}
$$

The second term on the left side is the value that belongs to old debt-holders just after the new debt $I_{B}$ is issued. New debt-holders have the same priority as the old ones, and both of them claim $L^{*(1)}$ in sum. $L^{*(1)}$ is evaluated as $B^{(1)}$, which is divided between the new debt-holders and the old ones with proportions of $\left(1-\frac{L^{*(0)}}{L^{*(1)}}\right)$ and $\frac{L^{*(0)}}{L^{*(1)}}$. Since rational investors pay $I_{B}$ for the value of $\left(1-\frac{L^{*(0)}}{L^{*(1)}}\right) B^{(1)}$, Equation (16) holds. The value of old debt $\frac{L^{*(0)}}{L^{*(1)}} B^{(1)}$ does not always maintain the original $B^{(0)}$. When the former is smaller than the latter, the old debt-holders lose their money.

The amount of the equity issue is $I_{S}$ when the investment is implemented. What is the relation of equity values concerning the investment? If the investment is profitable, the wealth of 
old shareholders must increase because of capital gain. When the investment is not executed, the price of a share of stock is $P_{S}^{(0)}$, and the outstanding number of shares is $n_{S}^{(0)}$. Then, the equity value is $S_{L}^{(0)}=n_{S}^{(0)} P_{S}^{(0)}$. When the investment is executed, the share price is $P_{S}^{(1)}$ and the outstanding number is $n_{S}^{(1)}$. Since the issued price of new equity is $P_{S}^{(1)}$, the number of new shares is $I_{S} / P_{S}^{(1)}$. The next equation is developed.

$$
\begin{aligned}
S_{L}^{(1)} & =n_{S}^{(1)} P_{S}^{(1)}=\left(n_{S}^{(0)}+\frac{I_{S}}{P_{S}^{(1)}}\right) P_{S}^{(1)} \\
& =S_{L}^{(0)}+I_{S}+n_{S}^{(0)}\left(P_{S}^{(1)}-P_{S}^{(0)}\right)
\end{aligned}
$$

That is, the equity value under the investment, $S_{L}^{(1)}$, is decomposed into three parts: 1) the original equity value without the investment, $\left.S_{L}^{(0)}: 2\right)$ the value of the newly issued shares owned by new shareholders, $I_{S}$ : and 3 ) the benefit to old shareholders owing to capital gain of the original shares, $n_{S}^{(0)}\left(P_{S}^{(1)}-P_{S}^{(0)}\right)$. When the firm is operated in the interest of old shareholders, the investment is executed if and only if $P_{S}^{(1)}$ is larger than or equal to $P_{S}^{(0)}$. From Equation (17), the relationship between equity values are summarized into

$$
P_{S}^{(1)} \geq P_{S}^{(0)} \Leftrightarrow \quad S_{L}^{(1)} \geq S_{L}^{(0)}+I_{S}
$$

Consider an investment plan where $P_{S}^{(1)}=P_{S}^{(0)}$ holds. This investment is marginal in terms of whether or not old shareholders profit from executing it. Then equity values satisfy

$$
S_{L}^{(1)}=S_{L}^{(0)}+I_{S}
$$

We focus on the following simultaneous equations:

$$
\begin{gathered}
\sigma_{Z}^{*(1)}=\arg \max _{\sigma_{Z}} S_{L}\left(\omega_{Z}^{(1)}, \alpha ; L^{*(1)}, \mu_{Z}^{*(1)}, \sigma_{Z}\right), \\
\mu_{Z}^{*(1)}=\omega_{Z}^{(1)}-\alpha L^{*(1)}, \\
\left(1-\frac{L^{*(0)}}{L^{*(1)}}\right) B\left(\omega_{Z}^{(1)}, \alpha ; L^{*(1)}, \mu_{Z}^{*(1)}, \sigma_{Z}^{*(1)}\right)=I_{B}, \\
S_{L}\left(\omega_{Z}^{(1)}, \alpha ; L^{*(1)}, \mu_{Z}^{*(1)}, \sigma_{Z}^{*(1)}\right)-S_{L}\left(\omega_{Z}^{(0)}, \alpha ; L^{*(0)}, \mu_{Z}^{*(0)}, \sigma_{Z}^{*(0)}\right)=I_{S} .
\end{gathered}
$$

Equations (16) and (18) simply rewrite the preceding two as functions. Equation (16) is concerned with the debt financing. Equation (18) is the issue of new equity when the investment is marginal. In Equation (14), $\sigma_{Z}$ is decided according to the asset substitution. Equation (15) is the constraint due to the agency costs of debt. The system of these four equations is 
denoted as a basic form. We know the values of the variables with superscript ${ }^{(0)}$. If $I_{S}$ and $I_{B}$ are given, then four variables $\left(\omega_{Z}^{(1)}, \mu_{Z}^{*(1)}, \sigma_{Z}^{*(1)}\right.$, and $\left.L^{*(1)}\right)$ can be solved from the four equations. Intuitively, using Equation (14) for $\sigma_{Z}^{*(1)}$ and Equation (15) for $\mu_{Z}^{*(1)}$, the solutions of this system are reduced to searching for two unknowns, $L^{*(1)}$ and $\omega_{Z}^{(1)}$, that satisfy Equations (16) and (18).

The solutions $\omega_{Z}^{(1)}, \mu_{Z}^{*(1)}, \sigma_{Z}^{*(1)}$, and $L^{*(1)}$ illustrate the case where the firm has implemented an investment with a minimum return, below which old shareholders would make a loss. Hence,

$$
R_{q} \equiv \frac{\omega_{Z}^{(1)}-\omega_{Z}^{(0)}-I}{I}
$$

is the required return on the investment. If return on an investment plan is above this value, executing it increases shareholders' wealth. Otherwise, shareholders' wealth decreases. The required return computed by this method plays a role on a cut-off or hurdle rate on investment.

The above discussion supposes that values of $I_{B}$ and $I_{S}$ are exogenously given. This means that we know how the investment is financed. Even if the amount of investment $I$ is known in advance, however, $R_{q}$ is never computed without specifying $I_{B}$ and $I_{S}$. If $I_{B}$ changes $R_{q}$, minimizing $R_{q}$ is best for maximizing the shareholders' wealth. If $R_{q}$ decreases, an investment plan that forces the share price to decline might be changed to a profitable one that increases the share price. Therefore, the optimal method of financing investment is to decide the value of $I_{B}$ through solving

$$
\min _{I_{B}} R_{q}, \quad \text { for } 0 \leq I_{B} \leq I .
$$

\subsection{Financing Investment}

We begin with the simplest case, where investment scales up a firm proportionally. In this model, a firm is homogeneous of degree one with respect to its size. If the investment enlarges the firm in proportion, the required return on investment must be equal to the earnings ratio of the firm, $R O A$. In fact, it is easy to confirm that $R_{q}$ defined in Equation (19) is equal to $R_{R O A}$ defined in Equation (13), when the firm is homogeneous of degree one.

There are two conditions for the investment that maintains a firm's constant return to scale. One is that a debt ratio after the investment is the same as before:

$$
\frac{I_{S}}{I_{B}}=\frac{S^{(0)}}{B^{(0)}}=\frac{S^{(1)}}{B^{(1)}} .
$$


Here, the proportion of debt financing over the amount of investment, $I_{B} / I$, is equal to the debt ratio of the capital structure. Since $S^{(1)}-S^{(0)}=I_{S}$ holds for the marginal investment, a simple calculation leads to $B^{(1)}-B^{(0)}=I_{B}$. Comparing this with Equation (16), we obtain

$$
\frac{L^{*(0)}}{L^{*(1)}} B^{(1)}=B^{(0)},
$$

which means that old debt-holders do not make a loss from the investment.

In the basic form presented above, the incentive of the asset substitution makes old debtholders lose and makes old shareholders gain from investment. Since the transfer of wealth arises among investors, this investment does not proportion a firm to its size. For the investment that scales up a firm proportionally, it is necessary that old debt-holders do not lose money from it. New debt $I_{B}$ associated with the investment has the same priority for the firm as old debt $B^{(0)}$. Although the new debt issue might dilute them, Equation (21) shows that the old debt-holders keep the same value $B^{(0)}$ as long as the investment purely proportions a firm.

The other condition is constraint on $\sigma_{Z}^{*(1)}$, which represents a business risk. It is possible that asset substitution arises whenever a manager chooses $\sigma_{Z}^{*(1)}$ as he/she likes. This possibility must be ruled out for the proportional scaling-up investment. When $\omega_{Z}$ increases by $c$ times, the standard deviation also increases by $c$ times.

$$
\omega_{Z}^{(1)}=c \omega_{Z}^{(0)} \Rightarrow \sigma_{Z}^{*(1)}=c \sigma_{Z}^{*(0)}
$$

In other words, the next relation is obtained:

$$
\sigma_{Z}^{*(1)}=\frac{\omega_{Z}^{(1)}}{\omega_{Z}^{(0)}} \sigma_{Z}^{*(0)} .
$$

These two conditions enable us to formulate the required return on the investment that maintains a firm's constant return to scale. First, in order to finance the investment $I$, the amount of which is exogenously given, raise cash $I_{B}$ with new debt and $I_{S}$ with new shares so that $I_{B} / I$ is equal to the original debt ratio, $B^{(0)} / V_{L}^{(0)}$. Next, with the values of $I_{B}$ and $I_{S}$ 
Table 3 The Required Return: Proportional Scaling-up Investment

\begin{tabular}{ccccccccc}
\multicolumn{2}{c}{ No Investment } \\
\hline$\omega_{Z}^{(0)}$ & $\mu_{Z}^{*(0)}$ & $\sigma_{Z}^{*(0)}$ & $L^{*(0)}$ & $S_{L}^{(0)}$ & $B^{(0)}$ & $V_{L}^{(0)}$ & $D R$ & $R O A$ \\
\hline 50.00 & 47.41 & 23.66 & 12.93 & 10.51 & 6.42 & 16.93 & 0.379 & 0.1144 \\
\hline
\end{tabular}

\begin{tabular}{cccccccccc}
\multicolumn{2}{l}{ Marginal Investment } \\
\hline$\omega_{Z}^{(1)}$ & $\mu_{Z}^{*(1)}$ & $\sigma_{Z}^{*(1)}$ & $L^{*(1)}$ & $S_{L}^{(1)}$ & $B^{(1)}$ & $V_{L}^{(1)}$ & $I_{B}$ & $I_{B} / I$ & $R R I$ \\
\hline 55.91 & 53.02 & 26.45 & 14.46 & 11.75 & 7.18 & 18.93 & 0.758 & 0.379 & 0.1144 \\
\hline
\end{tabular}

N.B) $\omega_{Z}, \mu_{Z}^{*}, \sigma_{Z}^{*}$ ! \$and $L^{*}$ are values in the case of one period equals 10 years. Superscript ${ }^{(0)}$ represents no investment and superscript ${ }^{(1)}$ represents the case that marginal investment is implemented. $D R$ is debt ratio $B / V_{L}$. $R O A$ is the before tax earnings ratio, which is converted to the case of one period equals one year from $R_{R O A}$ computed by Equation (13). $R R I$ is the before-tax required rate of return on investment and is converted to the one year case from $R_{q}$ in Equation (19).

given, we solve the following simultaneous equations.

$$
\begin{gathered}
\sigma_{Z}^{*(1)}=\frac{\omega_{Z}^{(1)}}{\omega_{Z}^{(0)}} \sigma_{Z}^{*(0)} \\
\mu_{Z}^{*(1)}=\omega_{Z}^{(1)}-\alpha L^{*(1)} \\
S_{L}\left(\omega_{Z}^{(1)}, \alpha ; L^{*(1)}, \mu_{Z}^{*(1)}, \sigma_{Z}^{*(1)}\right)-S_{L}\left(\omega_{Z}^{(0)}, \alpha ; L^{*(0)}, \mu_{Z}^{*(0)}, \sigma_{Z}^{*(0)}\right)=I_{S} \\
B\left(\omega_{Z}^{(1)}, \alpha ; L^{*(1)}, \mu_{Z}^{*(1)}, \sigma_{Z}^{*(1)}\right)-B\left(\omega_{Z}^{(0)}, \alpha ; L^{*(0)}, \mu_{Z}^{(0)}, \sigma_{Z}^{*(0)}\right)=I_{B}
\end{gathered}
$$

Equation (18) expresses the issue of new shares for the marginal investment, and Equation (15) describes the relation concerning the agency costs of debt. Both of them are the same as those in the basic form. Equations (22) and (23) are the ones different from those in the basic form. Equation (22) shows that the business risk $\sigma_{Z}^{*(1)}$ is proportional to firm's size. Equation (23) is the condition that the old debt-holders do not make a loss. As in the basic form, four variables $\omega_{Z}^{(1)}, \mu_{Z}^{*(1)}, \sigma_{Z}^{*(1)}$, and $L^{*(1)}$ are solved with these four equations. Lastly, from $\omega_{Z}^{(1)}$ and $\omega_{Z}^{(0)}$, we calculate the required return on the proportional scaling-up investment through Equation (19).

Solutions of the simultaneous equations are summarized in Table 3 for the case of proportional scaling-up investment when the firm in the previous example faces an investment opportunity of $I=2$. In order to finance $I=2$, the amount of new debt, $I_{B}$, is calculated so that the proportion of new debt is the same as the original debt ratio 0.379 . The value of $I_{B}$ is 


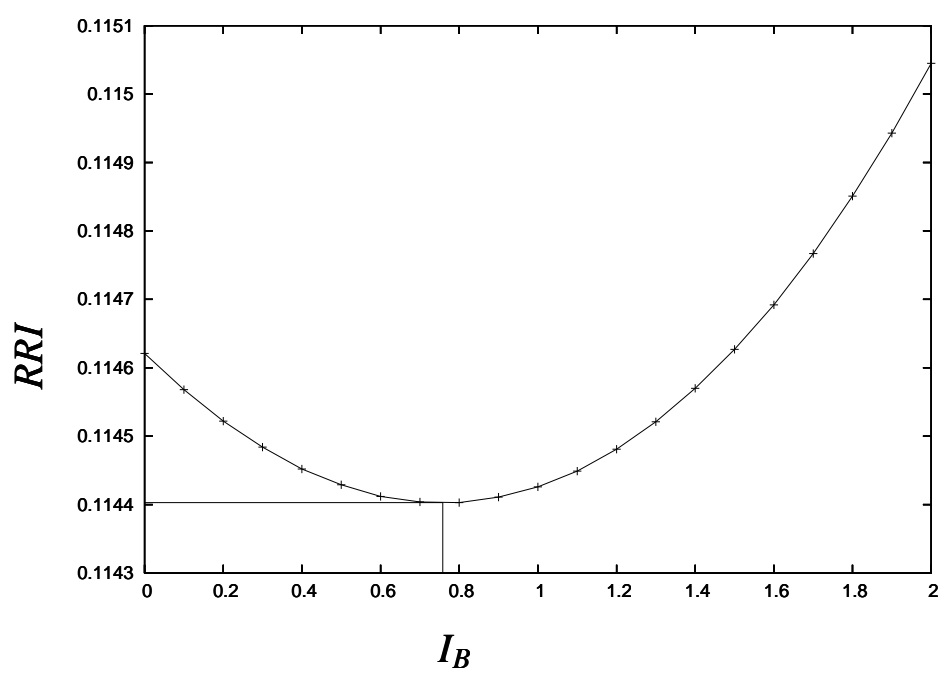

Figure 2 The Required Return and Debt Financing $I_{B}$ : Proportional Scaling-up Investment

0.758. The remaining 1.242 is $I_{S}$, which is the amount of the new share issue. The values of equity and debt change from 10.51 and 6.42 to 11.75 and 7.18 for $I_{S}$ and $I_{B}$. This marginal investment requires the firm to pay $L^{*(1)}=14.46$ to all debt-holders and to expect earnings of $\mu_{Z}^{(1)}=53.02$. These values give 55.91 to $\omega_{Z}^{(1)}$. Since earnings must be changed from $\omega_{Z}^{(0)}=50$ to $\omega_{Z}^{(1)}=55.91$ for $I=2$, the required return on the investment $R_{q}$ is $11.44 \%$ on the one-period equals one-year standard. See the $R R I$ on Table 3 , which is the value converted from $R_{q}$ in Equation (19) into the standard. $R R I$ for the proportional scaling-up investment is exactly equal to ROA in the case of no investment.

There is another method to determine $I_{B}$ and $I_{S}$. Figure 2 plots the required return $R_{q}$ with $I_{B}$ changed from 0 to 2 . The computation is the same in that $I=2$ is given and the simultaneous equations, (15), (18), (22), and (23), are solved. The increase in debt makes $R_{q}$ down at first but then makes $R_{q}$ up. $R_{q}$ depends on the method of financing the investment, and there is an optimal value of $I_{B}$ that minimizes $R_{q}$.

Homogeneity of degree one guarantees that the proportion of $I_{B}$ and $I_{S}$ that minimizes $R_{q}$ is always equal to the ratio of $B^{(0)}$ and $S_{L}^{(0)}$. Its proof is the same as the firm theory of microeconomics, which says that the ratio of inputs under the cost minimization does not depend on the quantity of production whenever there is constant return to scale. This numerical example shows that there exists the value of $I_{B}$ that minimizes $R_{q}$. It is optimal that debt is issued with the value of $I_{B}$ and that the remaining $I-I_{B}$ is financed with new 


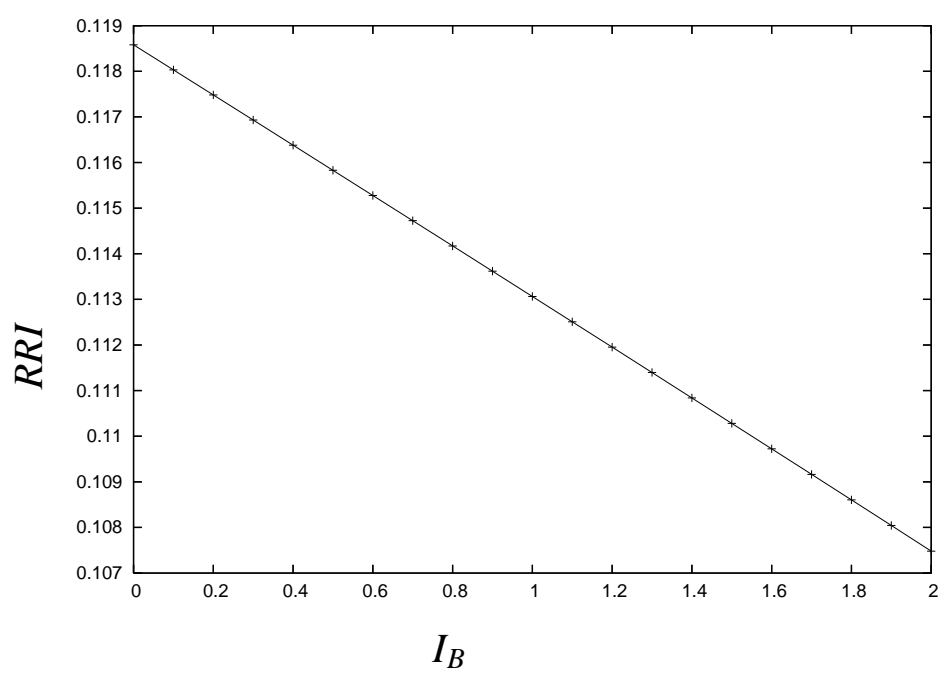

Figure 3 The Required Return and Debt Financing $I_{B}$ : Ordinary Investment

shares.

In sum, as long as we consider the proportional scaling-up investment, there are two methods for deciding its finance. The first is to divide $I$ between $I_{B}$ and $I_{S}$ by the firm's debt ratio. The second is to search $I_{B}$, which is to minimize $R_{q}$. Only in the investment that maintains the homogeneity, both the methods reach the same solutions. In the basic form under which investment does not necessarily scale up a firm proportionally, however, the former method is inappropriate because constant return to scale no longer holds. It is evident that only the second method preserves consistency in calculating the basic form.

\subsection{Calibration of the Basic Form of Investment}

If we are not restricted to the proportional scaling-up case, investment financing can bring about wealth transfer to shareholders to the detriment of debt-holders, which enables a firm to decrease the required return. Using calibration of the numerical example, we show that investment is executed in the interest of old shareholders.

The system of equations to be solved is the basic form mentioned above. The investment financing, $I_{B}$, is decided so that $R_{q}$ is minimized from Equation (20). The result of this calibration is summarized in Table $4 . I_{B}=2$ in the table means that all debt finance minimizes $R_{q}$ over the investment of $I=2$. Figure 3 confirms this fact. The figure plots $R_{q}$ when $I_{B}$ is between 0 and 2. $R_{q}$ declines monotonically with $I_{B}$. 
Table 4 The Required Return: Ordinary Investment

\begin{tabular}{|c|c|c|c|c|c|c|c|c|}
\hline \multicolumn{9}{|c|}{ No Investment } \\
\hline$\omega_{Z}^{(0)}$ & $\mu_{Z}^{*(0)}$ & $\sigma_{Z}^{*(0)}$ & $L^{*(0)}$ & $S_{L}^{(0)}$ & $B^{(0)}$ & $V_{L}^{(0)}$ & $D R$ & $R O A$ \\
\hline 50.00 & 47.41 & 23.66 & 12.93 & 10.51 & 6.42 & 16.93 & 0.379 & 0.1144 \\
\hline \multicolumn{9}{|c|}{ Marginal Investment } \\
\hline$\omega_{Z}^{(1)}$ & $\mu_{Z}^{*(1)}$ & $\sigma_{Z}^{*(1)}$ & $L^{*(1)}$ & $S_{L}^{(1)}$ & $B^{(1)}$ & $V_{L}^{(1)}$ & $I_{B}$ & $R R I$ \\
\hline 55.55 & 52.14 & 26.28 & 17.05 & 10.51 & 8.28 & 18.79 & 2.0 & 0.1075 \\
\hline
\end{tabular}

N.B.) See the footnote of Table 3.

The reason for this result is obvious. Compared to the proportional scaling-up investment, the more debt issued in financing, the more the old debt-holders are diluted. In the example, the old debt-holders had the value of 6.42. When the new debt of 2 is issued, their value declines to 6.28 , which is obtained by subtracting $I_{B}=2$ from $B^{(1)}=8.28$. Since the loss of the old debt-holders becomes old shareholders' gain, the required return on investment could decrease. In other words, old shareholders do not always take a loss from low return on investment if the wealth transfer from old debt-holders is large.

There is a comment about the computation of $\sigma_{Z}^{*(1)}$. In all the cases of no investment, $\sigma_{Z}^{*(0)}$ can be calibrated as an inner solution to maximize an equity value $S_{L}^{(0)}$. When the investment is implemented, however, $\sigma_{Z}^{*(1)}$ does not converge at all. Simulation results show that $S_{L}^{(1)}$ becomes a decreasing function of $\sigma_{Z}^{*(1)}$ in most cases, which means that $\sigma_{Z}^{*(1)}=0$ is optimum to maximize $S_{L}^{(1)}$. This is unrealistic and inappropriate. Thus, we assume the domain, $\left[\underline{\sigma_{Z}}, \overline{\sigma_{Z}}\right]$, over which $\sigma_{Z}^{*(1)}$ is to be searched. The lower limit, $\underline{\sigma_{Z}}$, is set as

$$
\underline{\sigma_{Z}}=\frac{\omega_{Z}^{(1)}}{\omega_{Z}^{(0)}} \sigma_{Z}^{*(0)},
$$

which is the value for the proportional scaling-up investment. The upper limit, $\overline{\sigma_{Z}}$, is assumed to be $\sigma_{Z}^{*(0)}$ times 1.3 .

The domain of $\sigma_{Z}^{*(1)}$ implies how much distorted the investment is without the constraint of proportional scaling-up. When $\omega_{Z}$ is enlarged by investment, $\sigma_{Z}$ is always larger. In the case of the proportional scaling-up investment, they are perfectly proportional. This is the lower limit of the domain. On the other hand, the incentive of asset substitution might increase $\sigma_{Z}$ to infinity, where the computation becomes impossible. Intuitively, we regard as the upper limit the increase in an original $\sigma_{Z}^{*(0)}$ by $30 \%$. 
The result of Table 4 confirms that the lower limit $\underline{\sigma_{Z}}$ is chosen as an optimal value of $\sigma_{Z}^{*(1)}$, which maximizes an equity value. In other words, it is optimal that the standard deviation of earnings is proportional to firm's size. This means that no incentive that further distorts investment exists as a real factor. The reason for an incentive that deviates from the proportional scaling-up investment lies in a financial factor, which leads to all debt financing.

In subsequent sections, we see several examples for simulation and application to real firms. In many cases, as well as Table 4, the above-mentioned optimal behaviors are observed:

First, investment should be financed by all debt issuance. Second, the choice of $\sigma_{Z}^{*(1)}$ should be the lower limit of the domain. The results of this numerical example are not extreme; in fact, they are very standard.

In this capital structure model, a firm has constant return to scale. The investment policy that maintains homogeneity is not optimal for this firm. If it issues the same proportion of debt as its debt ratio to finance the investment, and if it employs the required return equal to its original earnings ratio $R_{R O A}$, then the firm is proportionally scaled up by investment. The firm can gain more by breaking the homogeneity than by keeping it, however, in the case of investment through acquiring additional assets. By transferring wealth from old debt-holders to old shareholders when issuing more debt, the firm can decrease the required return $R_{q}$ and raise equity value more, increasing investment opportunity. As a result of the optimal behavior of investments, homogeneity disappears from the firm that has constant return to scale.

A firm should finance the entire amount of investment by debt, which means that the pecking order exists for investment financing. Although this model has optimal capital structure, all debt financing is preferred to the mix of debt and equity when a firm exercises investments. The discussion implies that investment financing is different from the firm's capital structure and that optimal capital structure is compatible with the pecking order hypothesis.

\section{Simulation}

In this section, simulation shows how endogenous variables change when one of exogenous parameters changes. Exogenous parameters are $\omega_{Z}^{(0)}, I, \alpha, k, \tau, \lambda$, and $\operatorname{corr}\left(\tilde{R}_{M}, \tilde{Z}\right)$. We investigate the effect of their change on endogenous variables.

A numerical example used in this simulation is the same as Table 1. The results of the simulation are summarized in Tables 5 through 11 . The computation is convergent for almost 
all cases, but there are a few which fail. We make a comment later about cases where the computation does not succeed.

There are two features for successful cases. One is that financing investment with all debt is optimal. The ratio $I_{B} / I$ in the tables is 1.0 for every case. In that situation, old debt-holders take a loss through the decrease in their debt value. We confirm this fact, comparing $B^{(0)}$ and OldB of the tables. OldB represents the debt value belonging to the old debt-holders at the time the investment is executed. OldB is smaller than $B^{(0)}$. As the result of all debt finance, the debt ratio with investment increases from that without it; $D R^{(1)}$ is larger than $D R^{(0)}$.

The other feature for success is the value of $\sigma_{Z}^{*(1)}$. For every case this is the lower limit of the domain $\left[\underline{\sigma_{Z}}, \overline{\sigma_{Z}}\right]$ for its optimal search. Optimum $\sigma_{Z}^{*(1)}$ is completely proportional to $\omega_{Z}^{(1)}$, which means that there is no incentive for which a firm takes more risk than proportionality. However, there is wealth transfer associated with issuing more debt than proportional. Because of the wealth transfer from the old debt-holders to old shareholders, the required return on investment, $R R I$, is smaller than the original earnings ratio, $R O A$.

We describe other results of the simulation as well. Table 5 demonstrates the effect of a change in $\omega_{Z}^{(0)}$. In the case of no investment where superscript ${ }^{(0)}$ is attached on a variable, the same numbers as those in Table 2 are shown. $D R^{(0)}$ and $R O A$ are unchanged regardless of $\omega_{Z}^{(0)}$ owing to the homogeneity of this model. Reflecting the investment finance, which forfeits it, $D R^{(1)}$ rises and $R R I$ is smaller than $R O A$. $R R I$ decreases slightly when $\omega_{Z}^{(0)}$ is up.

Table 6 presents the effect of a change in $I$ with $\omega_{Z}^{(0)}=50$ fixed. $R R I$ increases when $I$ rises. As demonstrated in Tables 5 and 6, the amount of investment relative to firm size has a positive relationship with the required return.

The effect of the agency cost parameter $\alpha$ is shown in Table 7. The debt ratio, $D R^{(0)}$, changes sensitively to $\alpha$. Comparing $\alpha=0.16$ and $\alpha=0.24$, a debt ratio declines from more than $50 \%$ to less than $20 \%$. Conventional wisdom tells us that the increase in the agency cost pushes up the cost of capital on investment. Table 7 supports this wisdom; the increase in $\alpha$ raises $R R I$.

The effect of the bankruptcy cost parameter $k$ is summarized in Table 8 , and the effect of tax rate $\tau$ in Table 9. When $k$ increases, or when $\tau$ decreases, the debt ratio, $D R^{(0)}$, declines. Table 8 shows that the increase in $k$ raises $R R I$; however, we do not know the effect of $\tau$ on RRI in Table 9.

Tables 10 and 11 illustrate the effects of parameters associated with capital markets. Table 
Table 5 The Change in $\omega_{Z}^{(0)}$

\begin{tabular}{cccccccccc}
\hline$\omega_{Z}^{(0)}$ & $\mu_{Z}^{*(0)}$ & $\sigma_{Z}^{*(0)}$ & $L^{*(0)}$ & \multicolumn{1}{c}{$S_{L}^{(0)}$} & \multicolumn{1}{c}{$B^{(0)}$} & \multicolumn{1}{c}{$V_{L}^{(0)}$} & $D R^{(0)}$ & $R O A$ & $C C_{\text {tax }}$ \\
$\omega_{Z}^{(1)}$ & $\mu_{Z}^{*(1)}$ & $\sigma_{Z}^{*(1)}$ & $L^{*(1)}$ & \multicolumn{1}{c}{$B^{(1)}$} & $D R^{(1)}$ & \multicolumn{1}{c}{$\mathrm{OldB}$} & $I_{B} / I$ & \multicolumn{1}{c}{$R R I$} & $R R I_{\text {tax }}$ \\
\hline 40.00 & 37.93 & 18.92 & 10.35 & 8.41 & 5.13 & 13.54 & 0.379 & 0.1144 & 0.0659 \\
45.56 & 42.67 & 21.56 & 14.48 & 7.00 & 0.454 & 5.00 & 1.000 & 0.1077 & 0.0592 \\
& & & & & & & & & \\
50.00 & 47.41 & 23.66 & 12.93 & 10.51 & 6.42 & 16.93 & 0.379 & 0.1144 & 0.0659 \\
55.55 & 52.14 & 26.28 & 17.05 & 8.29 & 0.441 & 6.29 & 1.000 & 0.1075 & 0.0591 \\
& & & & & & & & & \\
60.00 & 56.90 & 28.38 & 15.52 & 12.61 & 7.70 & 20.31 & 0.379 & 0.1144 & 0.0659 \\
65.54 & 61.62 & 31.00 & 19.62 & 9.57 & 0.431 & 7.57 & 1.000 & 0.1073 & 0.0590 \\
\hline
\end{tabular}

N.B) $D R^{(0)}$ and $D R^{(1)}$ are debt ratios computed from $B^{(0)} / V_{L}^{(0)}$ and $B^{(1)} / V_{L}^{(1)} . R O A$ is the value of the one-year basis converted from the $R_{R O A}$ of Equation (13). $R R I$ is the value of the one-year basis converted from the $R_{q}$ of Equation (19). $C C_{t a x}$ is the weighted average cost of capital given by Equation (1). OldB is the debt value, which belongs to old debt-holders and calculated from $B^{(1)}-I_{B} . I_{B} / I$ is the ratio of debt finance over the amount of investment. $I_{B} / I=1.0$ means that the investment is financed with all debt. $R R I_{\text {tax }}$ is an after-tax earnings ratio and is calculated from $(1-\tau) R R I$. Other parameters are $\alpha=0.2, k=0.4, \tau=0.45$, $I=2.0, \lambda=3.24$, and $\operatorname{corr}\left(\tilde{R}_{M}, \tilde{Z}\right)=0.2$.

Table 6 The Change in $I$

\begin{tabular}{ccccccccccc}
\hline \multirow{2}{*}{$I$} & $\omega_{Z}^{(0)}$ & $\mu_{Z}^{*(0)}$ & $\sigma_{Z}^{*(0)}$ & $L^{*(0)}$ & $S_{L}^{(0)}$ & $B^{(0)}$ & $V_{L}^{(0)}$ & $D R^{(0)}$ & $R O A$ & $C C_{\text {tax }}$ \\
& $\omega_{Z}^{(1)}$ & $\mu_{Z}^{*(1)}$ & $\sigma_{Z}^{*(1)}$ & $L^{*(1)}$ & $B^{(1)}$ & $D R^{(1)}$ & \multicolumn{1}{c}{$\mathrm{OldB}$} & $I_{B} / I$ & $R R I$ & $R R I_{\text {tax }}$ \\
\hline \multirow{2}{*}{1.0} & 50.00 & 47.41 & 23.66 & 12.93 & 10.51 & 6.42 & 16.93 & 0.379 & 0.1144 & 0.0659 \\
& 52.76 & 49.77 & 24.96 & 14.97 & 7.35 & 0.412 & 6.35 & 1.000 & 0.1070 & 0.0589 \\
& & & & & & & & & & \\
\multirow{2}{*}{2.0} & 50.00 & 47.41 & 23.66 & 12.93 & 10.51 & 6.42 & 16.93 & 0.379 & 0.1144 & 0.0659 \\
& 55.55 & 52.14 & 26.28 & 17.05 & 8.29 & 0.441 & 6.29 & 1.000 & 0.1075 & 0.0591 \\
& & & & & & & & & & \\
\multirow{2}{*}{5.0} & 50.00 & 47.41 & 23.66 & 12.93 & 10.51 & 6.42 & 16.93 & 0.379 & 0.1144 & 0.0659 \\
& 64.04 & 59.33 & 30.30 & 23.52 & 11.11 & 0.514 & 6.11 & 1.000 & 0.1087 & 0.0598 \\
\hline
\end{tabular}

N.B) Other parameters are $\alpha=0.2, k=0.4, \tau=0.45, \lambda=3.24$, and $\operatorname{corr}\left(\tilde{R}_{M}, \tilde{Z}\right)=0.2$. See the footnote of Table 5 . 
Table 7 The Change in $\alpha$

\begin{tabular}{ccccccccccc}
\hline \multirow{2}{*}{$\alpha$} & $\omega_{Z}^{(0)}$ & $\mu_{Z}^{*(0)}$ & $\sigma_{Z}^{*(0)}$ & $L^{*(0)}$ & \multicolumn{1}{c}{$S_{L}^{(0)}$} & $B^{(0)}$ & $V_{L}^{(0)}$ & $D R^{(0)}$ & $R O A$ & $C C_{\text {tax }}$ \\
& $\omega_{Z}^{(1)}$ & $\mu_{Z}^{*(1)}$ & \multicolumn{1}{c}{$\sigma_{Z}^{*(1)}$} & $L^{*(1)}$ & \multicolumn{1}{c}{$B^{(1)}$} & \multicolumn{1}{c}{$D R^{(1)}$} & \multicolumn{1}{c}{$\mathrm{OldB}$} & $I_{B} / I$ & $R R I$ & $R R I_{\text {tax }}$ \\
\hline \multirow{2}{*}{0.16} & 50.00 & 47.00 & 20.89 & 18.73 & 8.49 & 9.27 & 17.76 & 0.522 & 0.1091 & 0.0599 \\
& 55.20 & 51.54 & 23.07 & 22.84 & 11.11 & 0.567 & 9.11 & 1.000 & 0.1002 & 0.0551 \\
& & & & & & & & & & \\
\multirow{2}{*}{0.20} & 50.00 & 47.41 & 23.66 & 12.93 & 10.51 & 6.42 & 16.93 & 0.379 & 0.1144 & 0.0659 \\
& 55.55 & 52.14 & 26.28 & 17.05 & 8.29 & 0.441 & 6.29 & 1.000 & 0.1075 & 0.0591 \\
& & & & & & & & & & \\
\multirow{2}{*}{0.24} & 50.00 & 48.41 & 24.84 & 6.62 & 13.16 & 3.39 & 16.55 & 0.205 & 0.1169 & 0.0717 \\
& 55.83 & 53.29 & 27.74 & 10.62 & 5.31 & 0.288 & 3.31 & 1.000 & 0.1130 & 0.0622 \\
\hline
\end{tabular}

N.B) Other parameters are $k=0.4, \tau=0.45, I=2, \lambda=3.24$, and $\operatorname{corr}\left(\tilde{R}_{M}, \tilde{Z}\right)=0.2$. See the footnote of Table 5.

Table 8 The Change in $k$

\begin{tabular}{|c|c|c|c|c|c|c|c|c|c|c|}
\hline$k$ & $\begin{array}{c}\omega_{Z}^{(0)} \\
\omega_{Z}^{(1)} \\
\end{array}$ & $\begin{array}{l}\mu_{Z}^{*(0)} \\
\mu_{Z}^{*(1)} \\
\end{array}$ & $\begin{array}{c}\sigma_{Z}^{*(0)} \\
\sigma_{Z}^{*(1)}\end{array}$ & $\begin{array}{l}L^{*(0)} \\
L^{*(1)}\end{array}$ & $\begin{array}{l}S_{L}^{(0)} \\
B^{(1)} \\
\end{array}$ & $\begin{array}{c}B^{(0)} \\
D R^{(1)} \\
\end{array}$ & $\begin{array}{c}V_{L}^{(0)} \\
\text { OldB } \\
\end{array}$ & $\begin{array}{c}D R^{(0)} \\
I_{B} / I \\
\end{array}$ & $\begin{array}{c}R O A \\
R R I \\
\end{array}$ & $\begin{array}{l}C C_{\text {tax }} \\
R R I_{\text {tax }} \\
\end{array}$ \\
\hline \multirow{2}{*}{0.2} & 50.00 & 45.78 & 19.18 & 21.12 & 7.33 & 10.68 & 18.01 & 0.593 & 0.1075 & 0.0565 \\
\hline & 55.15 & 50.12 & 21.15 & 25.13 & 12.53 & 0.631 & 10.53 & 1.000 & 0.0992 & 0.0546 \\
\hline \multirow{2}{*}{0.4} & 50.00 & 47.41 & 23.66 & 12.93 & 10.51 & 6.42 & 16.93 & 0.379 & 0.1144 & 0.0659 \\
\hline & 55.55 & 52.14 & 26.28 & 17.05 & 8.29 & 0.441 & 6.29 & 1.000 & 0.1075 & 0.0591 \\
\hline \multirow{2}{*}{0.5} & 50.00 & 48.02 & 25.69 & 9.89 & 11.67 & 4.88 & 16.55 & 0.295 & 0.1169 & 0.0698 \\
\hline & 55.70 & 52.89 & 28.62 & 14.06 & 6.75 & 0.367 & 4.75 & 1.000 & 0.1105 & 0.0608 \\
\hline
\end{tabular}

N.B) Other parameters are $\alpha=0.2, \tau=0.45, I=2, \lambda=3.24$, and $\operatorname{corr}\left(\tilde{R}_{M}, \tilde{Z}\right)=0.2$. See the footnote of Table 5 .

10 is the case of $\lambda$. Table 11 is about $\operatorname{corr}\left(\tilde{R}_{M}, \tilde{Z}\right)$. It is intuitively said that the increases in $\lambda$ or $\operatorname{corr}\left(\tilde{R}_{M}, \tilde{Z}\right)$ raise the required return on investment because investors in capital markets require more. The results of these computations support that supposition. However, the computation always fails when $\lambda$ or $\operatorname{corr}\left(\tilde{R}_{M}, \tilde{Z}\right)$ is negative. Since the negative values of $\lambda$ or $\operatorname{corr}\left(\tilde{R}_{M}, \tilde{Z}\right)$ are sometimes observed in actual data, this fact might prove a defect in this model.

Here, we make a comment on the weighted average cost of capital (WACC) defined in Equation (1). To use the WACC as the required return on investment lacks consistency with 
Table 9 The Change in $\tau$

\begin{tabular}{ccccccccccc}
\hline \multirow{2}{*}{$\tau$} & $\omega_{Z}^{(0)}$ & $\mu_{Z}^{*(0)}$ & $\sigma_{Z}^{*(0)}$ & $L^{*(0)}$ & \multicolumn{1}{c}{$S_{L}^{(0)}$} & \multicolumn{1}{c}{$B^{(0)}$} & $V_{L}^{(0)}$ & $D R^{(0)}$ & $R O A$ & $C C_{\text {tax }}$ \\
& $\omega_{Z}^{(1)}$ & $\mu_{Z}^{*(1)}$ & \multicolumn{1}{c}{$\sigma_{Z}^{*(1)}$} & $L^{*(1)}$ & \multicolumn{1}{c}{$B^{(1)}$} & \multicolumn{1}{c}{$D R^{(1)}$} & \multicolumn{1}{c}{ OldB } & $I_{B} / I$ & $R R I$ & $R R I_{\text {tax }}$ \\
\hline \multirow{2}{*}{0.40} & 50.00 & 48.79 & 23.84 & 6.03 & 14.45 & 3.15 & 17.59 & 0.179 & 0.1101 & 0.0726 \\
& 55.55 & 53.56 & 26.48 & 9.95 & 5.08 & 0.260 & 3.08 & 1.000 & 0.1074 & 0.0644 \\
& & & & & & & & & & \\
\multirow{2}{*}{0.45} & 50.00 & 47.41 & 23.66 & 12.93 & 10.51 & 6.42 & 16.93 & 0.379 & 0.1144 & 0.0659 \\
& 55.55 & 52.14 & 26.28 & 17.05 & 8.29 & 0.441 & 6.29 & 1.000 & 0.1075 & 0.0591 \\
& & & & & & & & & & \\
\multirow{2}{*}{0.50} & 50.00 & 46.04 & 19.63 & 19.81 & 7.35 & 9.84 & 17.20 & 0.572 & 0.1126 & 0.0553 \\
& 55.34 & 50.56 & 21.73 & 23.91 & 11.67 & 0.613 & 9.67 & 1.000 & 0.1032 & 0.0516 \\
\hline
\end{tabular}

N.B) Other parameters are $\alpha=0.2, k=0.4, I=2, \lambda=3.24$, and $\operatorname{corr}\left(\tilde{R}_{M}, \tilde{Z}\right)=0.2$. See the footnote of Table 5.

Table 10 The Change in $\lambda$

\begin{tabular}{|c|c|c|c|c|c|c|c|c|c|c|}
\hline$\lambda$ & $\begin{array}{l}\omega_{Z}^{(0)} \\
\omega_{Z}^{(1)} \\
\end{array}$ & $\begin{array}{l}\mu_{Z}^{*(0)} \\
\mu_{Z}^{*(1)} \\
\end{array}$ & $\begin{array}{l}\sigma_{Z}^{*(0)} \\
\sigma_{Z}^{*(1)}\end{array}$ & $\begin{array}{l}L^{*(0)} \\
L^{*(1)}\end{array}$ & $\begin{array}{l}S_{L}^{(0)} \\
B^{(1)} \\
\end{array}$ & $\begin{array}{c}B^{(0)} \\
D R^{(1)}\end{array}$ & $\begin{array}{c}V_{L}^{(0)} \\
\text { OldB }\end{array}$ & $\begin{array}{c}D R^{(0)} \\
I_{B} / I \\
\end{array}$ & $\begin{array}{l}R O A \\
R R I\end{array}$ & $\begin{array}{l}C C_{\text {tax }} \\
R R I_{\text {tax }}\end{array}$ \\
\hline \multirow{2}{*}{1.62} & 50.00 & 47.29 & 26.82 & 13.53 & 11.81 & 6.60 & 18.41 & 0.358 & 0.1051 & 0.0592 \\
\hline & 55.01 & 51.39 & 38.37 & 18.13 & 7.88 & 0.400 & 5.88 & 1.000 & 0.0963 & 0.0529 \\
\hline \multirow{2}{*}{3.24} & 50.00 & 47.41 & 23.66 & 12.93 & 10.51 & 6.42 & 16.93 & 0.379 & 0.1144 & 0.0659 \\
\hline & 55.55 & 52.14 & 26.28 & 17.05 & 8.29 & 0.441 & 6.29 & 1.000 & 0.1075 & 0.0591 \\
\hline \multirow{2}{*}{4.85} & 50.00 & 47.38 & 21.14 & 13.12 & 9.20 & 6.61 & 15.81 & 0.418 & 0.1221 & 0.0707 \\
\hline & 55.96 & 52.52 & 23.66 & 17.16 & 8.48 & 0.480 & 6.48 & 1.000 & 0.1153 & 0.0634 \\
\hline \multirow{2}{*}{-1.62} & 50.00 & 46.34 & 41.61 & 18.28 & 15.15 & 8.39 & 23.55 & 0.356 & 0.0782 & 0.0393 \\
\hline & \multicolumn{10}{|c|}{ not converge } \\
\hline
\end{tabular}

N.B) Other parameters are $\alpha=0.2, k=0.4, \tau=0.45, I=2$, and $\operatorname{corr}\left(\tilde{R}_{M}, \tilde{Z}\right)=0.2$. See the footnote of Table 5.

assumptions on which this model depends. The required return on investment should be calculated endogenously as the RRI. How different are the WACC and RRI? Values of the WACC are displayed in $C C_{t a x}$ in Tables 5 through 11. To be compared with them, $R R I_{\text {tax }}$ is converted into an after-tax value from $R R I$. For almost all cases, $C C_{t a x}$ is larger than $R R I_{t a x}$ 
Table 11 The Change in $\operatorname{corr}\left(\tilde{R}_{M}, \tilde{Z}\right)$

\begin{tabular}{|c|c|c|c|c|c|c|c|c|c|c|}
\hline $\operatorname{corr}\left(\tilde{R}_{M}, \tilde{Z}\right)$ & $\begin{array}{c}\omega_{Z}^{(0)} \\
\omega_{Z}^{(1)} \\
\end{array}$ & $\begin{array}{l}\mu_{Z}^{*(0)} \\
\mu_{Z}^{*(1)} \\
\end{array}$ & $\begin{array}{l}\sigma_{Z}^{*(0)} \\
\sigma_{Z}^{*(1)} \\
\end{array}$ & $\begin{array}{l}L^{*(0)} \\
L^{*(1)} \\
\end{array}$ & $\begin{array}{c}S_{L}^{(0)} \\
B^{(1)} \\
\end{array}$ & $\begin{array}{c}B^{(0)} \\
D R^{(1)} \\
\end{array}$ & $\begin{array}{c}V_{L}^{(0)} \\
\text { OldB } \\
\end{array}$ & $\begin{array}{c}D R^{(0)} \\
I_{B} / I \\
\end{array}$ & $\begin{array}{c}R O A \\
R R I \\
\end{array}$ & $\begin{array}{l}C C_{\text {tax }} \\
R R I_{\text {tax }}\end{array}$ \\
\hline \multirow{2}{*}{0.2} & 50.00 & 47.41 & 23.66 & 12.93 & 10.51 & 6.42 & 16.93 & 0.379 & 0.1144 & 0.0659 \\
\hline & 55.55 & 52.14 & 26.28 & 17.05 & 8.29 & 0.441 & 6.29 & 1.000 & 0.1075 & 0.0591 \\
\hline \multirow{2}{*}{0.4} & 50.00 & 47.22 & 18.95 & 13.90 & 7.89 & 7.11 & 15.00 & 0.474 & 0.1279 & 0.0735 \\
\hline & 56.29 & 52.72 & 21.34 & 17.87 & 8.99 & 0.533 & 6.99 & 1.000 & 0.1214 & 0.0668 \\
\hline \multirow{2}{*}{0.8} & 50.00 & 45.87 & 11.36 & 20.67 & 3.47 & 11.18 & 14.65 & 0.763 & 0.1306 & 0.0644 \\
\hline & 56.60 & 51.72 & 12.86 & 24.39 & 13.11 & 0.791 & 11.11 & 1.000 & 0.1268 & 0.0697 \\
\hline \multirow{2}{*}{-0.1} & 50.00 & 46.34 & 41.61 & 18.28 & 15.15 & 8.39 & 23.55 & 0.356 & 0.0782 & 0.0393 \\
\hline & \multicolumn{2}{|c|}{ not converge } & & & & & & & & \\
\hline
\end{tabular}

N.B) Other parameters are $\alpha=0.2, k=0.4, \tau=0.45, I=2$, and $\lambda=3.24$. See the footnote of Table 5 .

by $10-20$ percent, significant difference. ${ }^{* 7}$

\section{Application to Actual Firms}

This section applies the method of this study to actual firms. We compare the required return computed from the model, $R R I_{\text {tax }}$, with the weighted average cost of capital, $C C_{\text {tax }}$.

In the case of no investment, this model evaluates equity and debt, solving an optimal triad, $L^{*(0)}, \mu_{Z}^{*(0)}$, and $\sigma_{Z}^{*(0)}$, when two variables, $\omega_{Z}^{(0)}$ and $\alpha$, are set. Since equity and debt are evaluated as functions of $\omega_{Z}^{(0)}$ and $\alpha$, these estimates can be solved from equity and debt as their inverses. Data concerning equity and debt are available. We get an equity value by multiplying the share price by the outstanding number of shares. The proxy variable for a debt value is interest-bearing debt on the balance sheet. We can compute $\omega_{Z}^{(0)}, \alpha, L^{*(0)}, \mu_{Z}^{*(0)}$, and $\sigma_{Z}^{*(0)}$ for an actual firm from data. Then, based on the calibration, we derive the required return on investment for the firm.

${ }^{* 7} R R I$ is the before-tax value. Its after-tax number $R R I_{\text {tax }}$ is calculated from $R R I_{\text {tax }}=(1-\tau) R R I$. Earnings in this study is the lump-sum of ten years. The results of numerical examples and simulation show what is distributed to each year from the lump-sum. These kinds of conversion have several alternatives. This study produces results under the method which minimizes the difference between $C C_{\operatorname{tax}}$ and $R R I_{\text {tax }}$. Under an alternative the difference can expand dramatically. 
This study computes the required return for actual firms on the supposition that they invest an outlay amounting to $15 \%$ of the firm's value. We selected firms listed on the Tokyo Stock Exchange (TSE) 1st section in manufacturing sectors. Our experiment covers two periods. The first is the 10 fiscal years from 1974 to 1983 , and the second is the 10 fiscal years from 1984 to 1993 . These sets of 10 years are each regarded as one period. We call the former "period[1]" and the latter "period[2]." For each variable, an average over the period is employed. $S_{L}^{(0)}$ is the average market value of stock, and $B^{(0)}$ is the average interest-bearing debt. Data on capital market variables, $\mathrm{E}\left(\tilde{R}_{M}\right), \sigma\left(\tilde{R}_{M}\right), R_{F}$, and $\lambda$, about these periods are converted into a one period equals 10 years standard. $\operatorname{corr}\left(\tilde{R}_{M}, \tilde{Z}\right)$ is calibrated from a beta coefficient for the firm's equity return. A bankruptcy cost parameter, $k$, is assumed to be 0.3 for all the firms since we do not know what is valid. We assume that corporate tax rate, $\tau$, is 0.45 .

Table 12 summarizes the results of the computation. We calculated 515 firms for period[1] and 592 firms for period[2]. For period[1] and period[2], 471 and 578 firms, respectively, succeeded in computing the parameters of $\omega_{Z}^{(0)}$ and $\alpha$. This proves that the model in this study applies remarkably well to actual firms. Next we had 442 firms for period[1] and 576 firms for period[2] that succeeded with the basic form in Section 3.1. The number of firms for which the standard deviation converged on its lower bounds are 284 and 572, for period[1] and period[2], respectively. The rest of firm's standard deviation were convergent to the upper bound. While almost all firms for period[2] chose the lowest standard deviation as an optimum, more than $30 \%$ for period[1] tried to increase it. Although they intended to take more business risk for period[1], this incentive disappeared in period[2]. Furthermore, among those with the lowest standard deviation, there were 253 firms for period[1] and 455 firms for period[2] that financed investment with only debt issuance. At most $25 \%$ of the firms were willing to issue a mix of debt and equity; 31 firms for period[1] and 117 firms for period[2].

The upper bound of the standard deviation, $\overline{\sigma_{Z}}$, is set to a tentative value. When the standard deviation is convergent on it, other estimated parameters that depend on it are arbitrary. Firms' computations in this group are excluded, and we selected firms whose standard deviations are convergent on their lower bound. Table 13 compares the required return estimated from the model, $R R I_{t a x}$, with the WACC from data, $C C_{t a x} .{ }^{* 8}$ For these averages, $C C_{t a x}$ is

${ }^{* 8} C C_{\text {tax }}$ in Section 4 is estimated from the model's value in simulation. In Section 5 , where we focus on 
Table 12 Summary of Computation Results

\begin{tabular}{|c|c|c|}
\hline & \multicolumn{2}{|c|}{ the number of firms } \\
\hline & period[1] & period[2] \\
\hline manufacturing firms listed on TSE 1-st section (A) & 515 & 592 \\
\hline firms which succeed in the pre-investment computation (B) & 471 & 578 \\
\hline rate of success $(\mathrm{B}) /(\mathrm{A})$ & $91.5 \%$ & $97.6 \%$ \\
\hline firms which succeed in computing their required return $(C)$ & 442 & 576 \\
\hline rate of success $(\mathrm{C}) /(\mathrm{B})$ & $93.8 \%$ & $99.7 \%$ \\
\hline firms whose standard deviation converges to its upper bound & 158 & 4 \\
\hline firms whose standard deviation converges to its lower bound & 284 & 572 \\
\hline firms which finance their investment with debt only & 253 & 455 \\
\hline firms which finance their investment with the mix of debt and equity & 31 & 117 \\
\hline
\end{tabular}

Period[1] is ten years from 1974 fiscal year to 1983. Period[2] is ten years from 1984 fiscal year to 1993. "pre-investment computation" means that we can estimate $\omega_{Z}^{(0)}, \alpha, \sigma_{Z}^{*(0)}, L^{*(0)}$, and $\mu_{Z}^{*(0)}$. "computing required return" means that we can estimate parameters of the basic form in Section 3.1.

larger than $R R I_{\operatorname{tax}}$ over both periods. $C C_{\operatorname{tax}}$ has twice as large a standard deviation (s.d.) as $R R I_{\text {tax }}$.

diff designates the rate of difference between $C C_{\operatorname{tax}}$ and $R R I_{\operatorname{tax}}$, and its positive value means that $C C_{\text {tax }}$ is larger than $R R I_{\text {tax }}$. diff varies between period[1] and period[2]. Its sample average is $0.78 \%$ over period[1] and $18.54 \%$ over period[2]. While only 130 firms, less than half, have a positive value of diff for period[1], almost all firms have positive diff for period[2]. Figure 4 presents histograms for diff. Distribution for period[1] is positively skewed, and it is positively shifted from period[1] to period[2]. Which is larger between $C C_{\text {tax }}$ and $R R I_{\text {tax }}$ is obscure for period[1], but in period[2] $C C_{\text {tax }}$ tend to be larger.

Table 13 shows three test statistics related to the difference between $R R I_{\operatorname{tax}}$ and $C C_{\operatorname{tax}}$. "t-test" is the result of the ordinary t-value on the difference in averages. "diff-Z" is the $\mathrm{Z}$-value computed from the hypothesis that diff is zero. "Wilcoxon" is the non-parametric statistics for their significant difference. All of the results exhibit the fact that $R R I_{\text {tax }}$ is not

comparing the model with an actual firm, $C C_{\operatorname{tax}}$ is computed from data. 

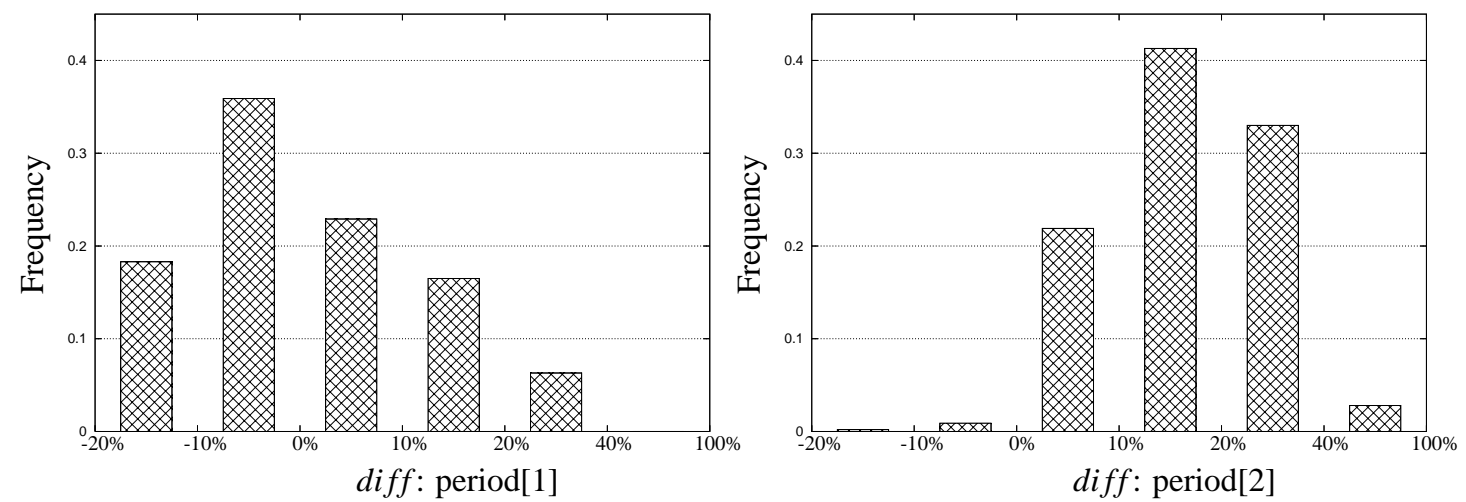

Figure 4 Histograms for The Rate of Difference, diff

different from $C C_{t a x}$ over period[1], but that there is a significant difference between them during period[2].

Table 13 calculates three correlation statistics between $R R I_{\text {tax }}$ and $C C_{\text {tax }}$. The ordinary correlation coefficient, "Pearson," is 0.816 for period[1] and 0.727 for period[2]. In light of non-parametric statistics, "Spearman" has almost the same values and "Kendall" has lower ones. These three coefficients for period[2] is lower than those for period[1]. All of them are significantly different from zero.

Table 14 reveals transition as to whether $R R I_{\text {tax }}$ and $C C_{\text {tax }}$ decrease together from period[1] to period[2]. A total of 278 firms could compute $R R I_{\text {tax }}$ for both periods. For all the firms, $R R I_{\text {tax }}$ declines from period[1] to period[2], and the $C C_{\text {tax }}$ of 183 firms, more than $65 \%$, come down together.

In summary, the correlation and the transition find that $R R I_{\text {tax }}$ estimated from the model in this study suits to some extent with $C C_{t a x}$ computed from data, and that they are not irrelevant. These facts prove that the value of required return we compute is not meaningless. However, correlation coefficients are not very high, and $C C_{t a x}$ and $R R I_{\text {tax }}$ are significantly different for a period. The average of their difference is about $18 \%$, and it is highly probable that $C C_{\operatorname{tax}}$ is much larger than $R R I_{\text {tax }}$ for some firms. For these firms, considering their required return as the WACC leads to investment distortion. 
Table 13 Comparisons between $C C_{t a x}$ and $R R I_{t a x}$

\begin{tabular}{lrr}
\hline & period[1] & period[2] \\
\hline firms & 284 & 572 \\
$C C_{\text {tax }}$ & & \\
mean & 0.0832 & 0.0763 \\
s.d. & 0.0151 & 0.0091 \\
min & 0.0549 & 0.0557 \\
max & 0.1236 & 0.1092 \\
$R R I_{\text {tax }}$ & & \\
mean & 0.0822 & 0.0648 \\
s.d. & 0.0085 & 0.0046 \\
min & 0.0615 & 0.0550 \\
max & 0.1069 & 0.0791 \\
diff $=\left(C C_{\text {tax }}-R_{\text {RI }}\right) / R R I_{\text {tax }}$ & \\
mean & 0.0078 & 0.1774 \\
s.d. & 0.1140 & 0.0982 \\
min & -0.1988 & -0.1049 \\
max & 0.3625 & 0.5874 \\
diff $>0$ & 130 & 566 \\
\hline
\end{tabular}

difference: test statistics

$\begin{array}{lll}\text { t-test } & 1.832 & 41.71^{* *} \\ \text { diff-Z } & 1.155 & 43.22^{* *} \\ \text { Wilcoxon } & 0.856 & 20.68^{* *}\end{array}$

correlation

\begin{tabular}{lll} 
Pearson & $0.816^{* *}$ & $0.727^{* *}$ \\
Spearman & $0.809^{* *}$ & $0.732^{* *}$ \\
Kendall & $0.624^{* *}$ & $0.541^{* *}$ \\
\hline
\end{tabular}

Period[1] is ten years from 1974 fiscal year to 1983. Period[2] is ten years from 1984 fiscal year to 1993. RRI tax is the after-tax required return on investment estimated from the basic form of this study, and $C C_{\operatorname{tax}}$ is the weighted average cost of capital computed from the data. diff is the rate of their difference. "t-test" is the t-statistics under the hypothesis that $R R I_{\operatorname{tax}}$ and $C C_{\text {tax }}$ have the same mean. "diff-Z" denotes a Z-value under the hypothesis of diff $=0$. "Wilcoxon" is non-parametric statistics Z of the Wilcoxon test. "Pearson" is an ordinary correlation coefficient, and "Spearman" and "Kendall" are non-parametric rank correlations. * and ${ }^{* *}$ represent $5 \%$ and $1 \%$ significance levels. 
Table 14 Transition of $C C_{\text {tax }}$ and $R R I_{\text {tax }}$

\begin{tabular}{lcrr}
\hline & \multicolumn{2}{c}{$C C_{\text {tax }}$} \\
\cline { 2 - 3 } & down & up \\
\hline \multirow{2}{*}{$R R I_{\text {tax }}$} & down & 183 & 95 \\
& up & 0 & 0 \\
\hline \multirow{2}{*}{ total } & & \\
same movement & 278 \\
(percentage) & $183^{* *}$ & $(65.8 \%)$ \\
\hline
\end{tabular}

Period[1] is ten years from 1974 fiscal year to 1983. Period[2] is ten years from 1984 fiscal year to $1993 . R R I_{\text {tax }}$ is the required return on investment estimated from this model, and $C C_{t a x}$ is the weighted average cost of capital computed from the data. From period[1] to period[2] "down" means they decline. The number of firms whose $R R I_{\text {tax }}$ and $C C_{\text {tax }}$ move together is "same movement." From the large sample sign test, ${ }^{* *}$ indicates that they move the same way with $1 \%$ significance.

\section{Conclusion}

This study calculates the required return on investment through an extended capital structure model that includes the agency costs of debt. The weighted average cost of capital, which is standard in an investment decision, is obscure in that it lacks theoretical foundation beyond the Modigliani-Miller(1963) hypothesis. It is obvious that if a model is sufficiently applicable to an actual firm, the required return calculated from the model is more reliable than that calculated from the weighted average cost of capital.

Even if a firm has constant return to scale in a capital structure model, the investment strategy that maintains the homogeneity is not necessarily optimal. When the firm depends on outside cash to finance the investment, the wealth transfer to old shareholders at the sacrifice of old debt-holders enables the required return on investment to decrease from a value of the proportional scaling-up investment case. As the result of the transfer, the constant return to scale disappears for the investment.

The finance which makes old debt-holders lose as much as possible is to issue new debt of all the amount of investment. This means that the pecking order hypothesis holds for investment financing. It is true that the optimal capital structure exists over a firm itself in this model. Nevertheless, all debt financing is preferable to the mix of debt and equity issuance for 
investment. It is becoming popular to discuss which explains actual firms better, the pecking order hypothesis or the optimal capital structure theory. This study implies that we should not confuse investment financing with corporate capital structure. The more important is to construct a model that attempts to embrace both of them consistently, and this study is an example of this trial.

We examine the size of the difference between the required return estimated from this model and the weighted average cost of capital computed from data. Although they move together to some extent, there is a period when the WACC is $20 \%$ larger than the estimated required return in terms of sample averages. Since some firms overestimate their cut-off rate for investment, using the WACC is not always adequate.

\section{References}

[1] Arditti, F. D., and H. Levy. 1977. The Weighted Average Cost of Capital as a Cutoff rate: A Critical Analysis of the Classical Textbook Weighted Average. Financial Management 6: 24-34.

[2] Ben-Horim, M. 1979. Comment on "The Weighted Average Cost of Capital as a Cutoff Rate". Financial Management 8: 18-21.

[3] Boudreaux, K. J., and H. W. Long. 1979. The Weighted Average Cost of Capital as a Cutoff Rate: A Further Analysis. Financial Management 8: 7-14.

[4] Leland, H. E. 1998. Agency Costs, Risk Management, and Capital Structure. Journal of Finance 53: 1213-1243.

[5] Levy H., and M. Sarnat. 1990. Capital Investment and Financial Decisions(fourth edition). Prentice Hall.

[6] Morellec, E. 2004. Can Managerial Discretion Explain Observed Leverage Ratios? Review of Financial Studies 17: 257-294.

[7] Modigliani, F., and M. H. Miller. 1963. Corporate Income Taxes and the Cost of Capital: A Correction. American Economic Review 53: 433-443.

[8] Tsuji, Y. 2009. Measuring the Agency Costs of Debt: A Simplified Approach. mimeo. Available at SSRN. http://ssrn.com/abstract=997222 